


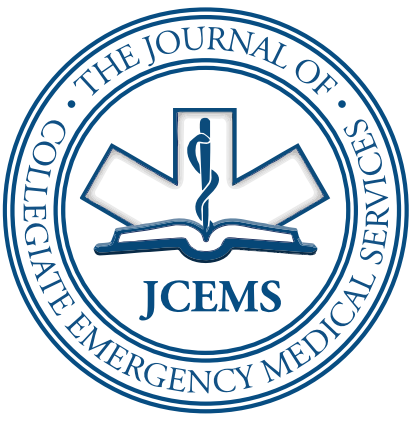

The Journal of

COLLEGIATE EMERGENCY MEDICAL SERVICES

The Official Journal of the National Collegiate Emergency Medical Services Foundation

\section{TABLE OF CONTENTS}

\section{Advice \& Practices}

4 Call to EMS Research: Disparities in

Recruitment and Retention of Black

Providers is an Issue We Cannot Ignore

Emily Forrest Hutchens

\section{Original Research}

$8 \quad$ Predicting Patient Volumes at Collegiate

Football Games

Abagayle E. Renko, Joshua M. Knapp, Susan J.

Boehmer, Joseph M. Kass; Dylan J. Degol, Jessica L.

Mann, Jeffrey S. Lubin

\section{Advice \& Practices}

6 Lessons from Early Vaccination of Campus EMS Providers at the University of

California, Davis

Lisa Mills, Nathan Trauernicht, Nathaniel

Hartinger

\section{Original Research}

16 Assessment of Bystander Intervention on EMS Transport Decisions for Cases of Alcohol Intoxication at a Small Liberal Arts College Bruno Di Nucci, Adam Fallah, Anamaria Alvarez, Parker Smith

\section{A MESSAGE FROM THE EDITOR-IN-CHIEF}

\section{JCEMS Readers,}

It is my great pleasure to announce that Chris Gaeta has been selected as our next Editor-in-Chief. For the past four years, it has been a privilege to serve the collegiate EMS community as your Editor-in-Chief and I have been humbled by everyone's support in helping to grow this journal. I look forward to remaining deeply involved on the Editorial Board, and I am beyond thrilled that someone with Chris's leadership and experience will be at the helm during our next stage of growth.

Prior to being selected as Editor-in-Chief, Chris served as our inaugural Director of Business Development. In this capacity, Chris oversaw a team focused on building partnerships and promoting collegiate EMS research, specifically through our research mentorship program, NCEMSF conference events, and outreach initiatives. Outside of JCEMS, Chris is an undergraduate student at Swarthmore college and is concurrently pursuing a Master's degree in Bioethics at the University of Pennsylvania. His published work has ranged from the role of collegiate EMS in the vaping pandemic to the financial implications of tele-neurology consults to novel diagnostic assays for COVID-19. Chris's leadership, vision, and passion for evidence-based medicine will ensure that JCEMS continues to advance research in the collegiate EMS community.

Thank you all for your continued support of JCEMS and for your service on our college and university campuses.

With appreciation,

Nicholas Friedman

Cover Photo Credit: University of Dayton Emergency Medical Services 


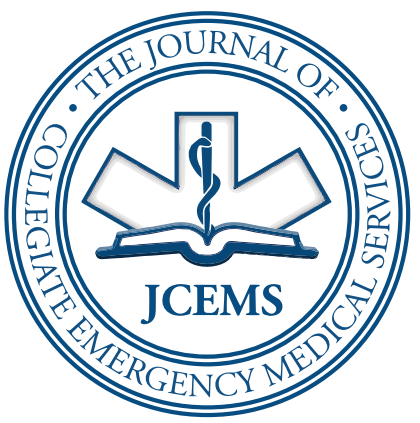

\section{The Journal of COLLEGIATE EMERGENCY MEDICAL SERVICES}

The Official Journal of the National Collegiate Emergency Medical Services Foundation

PUBLICATION INFORMATION

Editor

Christopher Gaeta, EMT-B • Editor-in-Chief

Editorial Board

Jose Victor L. Nable, MD, MS, NRP

Georgetown University School of Medicine, Washington, DC

Nicholas M.G. Friedman, BA, EMT

Stanford University School of Medicine, Stanford, CA

Matthew J. Levy, DO, MS, FACEP

The Johns Hopkins University School of Medicine, Baltimore, MD

Benjamin J. Lawner, DO, MS, EMT-P, FACEP

Temple University School of Medicine, Philadelphia, PA

David Goroff, MS, NRP

New Castle County EMS, New Castle, DE

Albert Jagoda, MD

Skidmore College, Saratoga Springs, NY

Brent Campbell, BA, AEMT-CC

Ambulance Service of Fulton County, Gloversville, NY

Patricia Bosen, MSN, FNP-C

Skidmore College, Saratoga Springs, NY

Joseph M. Grover, MD

University of North Caroline School of Medicine, Chapel Hill, NC

Lauren N. Gorstein, BA, EMT-B

Skidmore College, Saratoga Springs, NY

Michael W. Dailey, MD, FACEP, FAEMS

Albany Medical College, Albany, NY

Jeffrey S. Lubin, MD, MPH, FACEP, FAEMS

Penn State College of Medicine, Hershey, PA

Publishing \& Management

Max Moss, EMT • Managing Editor

Ernest Wang • Editorial Associate

Eason Cheung • Editorial Associate

Charisma Hasan • Editorial Associate

Brittany J. Dingler, MHS, PA-C • Senior Editorial Board Member, Co-Founder Andrew Chen, MPPA • Associate Manager of Layout and Graphic Design

News \& Outreach

Isabel Anzani • Social Media \& Outreach Editor

Special Programs

Michael Beautyman • Director of Mentorship Program

Joe Caruso • Associate Manager of Special Events

\section{General Information}

The Journal of Collegiate Emergency Medical Services (JCEMS) [ISSN 2576-3687] is the official scholarly, peer-reviewed journal of the National Collegiate Emergency Medical Services Foundation. JCEMS is published by the National Collegiate Emergency Medical Services Foundation.

Annual Subscription: Visit www.collegeems.com for information on purchasing institutional and personal annual subscriptions.

Reprints: Visit www.collegeems.com for information on purchasing reprints and single issues.

Correspondence (Editorial \& Business): Address mail to The Journal of Collegiate Emergency Medical Services, National Collegiate Emergency Medical Services Foundation, PO Box 93, West Sand Lake, NY 12196. Email: JCEMS@CollegeEMS. com

Correspondence (NCEMSF): Address mail to National Collegiate Emergency Medical Services Foundation, PO Box 93,West Sand Lake, NY 12196. Email: info@ ncemsf.org

Copyright: The Journal of Collegiate Emergency Medical Services is an open access publication. Individual authors retain copyright over their own articles. Articles are distributed under the terms of the Creative Commons Attribution 4.0 International (CC BY 4.0) License, which permits unrestricted use, distribution, and reproduction in any medium, provided the original author and source are credited. The full license is available at: https://creativecommons.org/licenses/by/4.0/. All other content in the journal is copyrighted by the National Collegiate Emergency Medical Services Foundation. All rights reserved.

Online availability: All articles published in print issues of JCEMS are available open access at https://www.collegeems.com. Additional content - not available in print issues - is also published on-line.

Disclaimers: The statements and opinions in articles or other content contained in JCEMS are solely those of the individual authors, contributors, advertisers, and sponsors, and do not represent those of JCEMS, the National Collegiate Emergency Medical Services Foundation, or any representatives, agents, or licensors. The appearance of advertisements does not represent a warranty, endorsement, or approval of the products or services advertised. JCEMS, the National Collegiate Emergency Medical Services Foundation, or any representatives, agents, or licensors make no warranties, representations, or other claims as to the accuracy or completeness of any articles or other content contained in JCEMS. JCEMS and NCEMSF disclaim responsibility for any injury to persons or property resulting from ideas, products, or other content referred to in articles or other content in JCEMS. EMS providers should always consult medical direction and local EMS protocols.

Instructions for Authors: Instructions for authors may be found in the JCEMS Guide for Authors at https://www.collegeems.com. Authors are required to abide by the latest guidelines available on-line at the time of submission.

Reviewers: JCEMS employs a double-blind peer review process for Original Research, Case Reports, and Reviews. The clinical and scientific quality of this publication relies on the rigorous and diligent reviews provided by independent reviewers with subject-matter expertise. JCEMS is grateful for all anonymous independent reviewers who dedicated their time and expertise to the collegiate EMS community. 


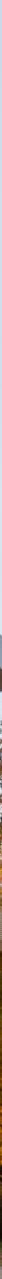

Submit to JCEMS: the official scholarly, peer-reviewed journal of the National Collegiate EMS Foundation.
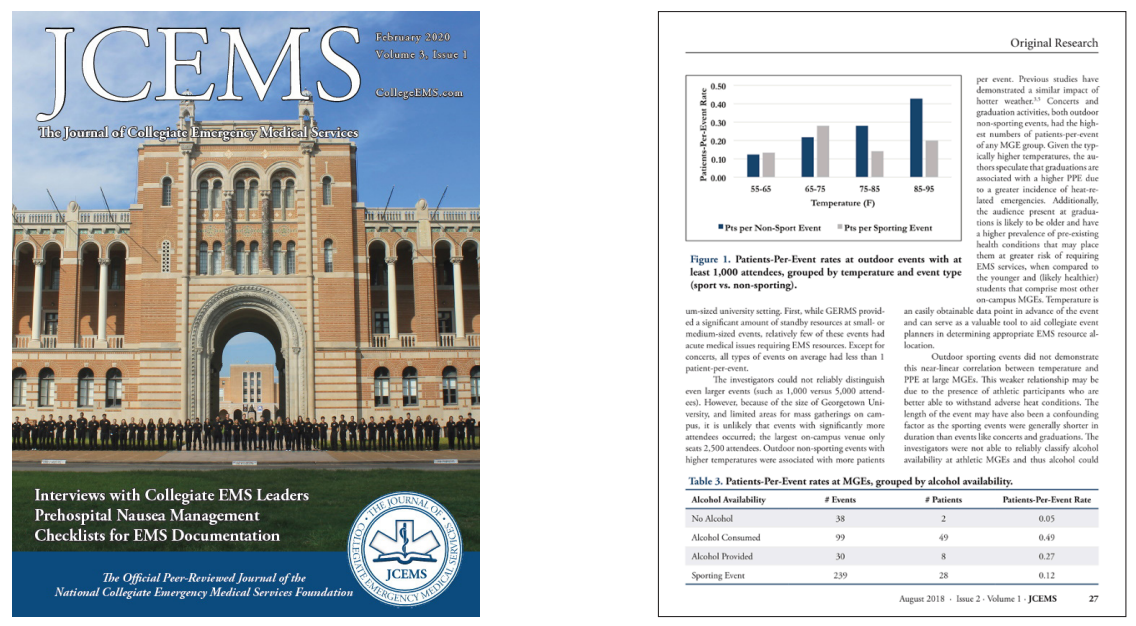

RESEARCH MENTORSHIP

We are committed to mentoring student researchers and authors. If you might be interested in conducting a study or submitting a manuscript for publication, consider applying to the JCEMS Research Mentorship Program. Additional details are available at www.CollegeEMS.com.

SUBMISSION GUIDELINES

View submission guide at: www.CollegeEMS.com

Send inquiries to:

Original research is prioritized. Case reports, reviews, and articles featuring perspectives and commentary are also invited. 


\title{
Call to EMS Research: Disparities in Recruitment and Retention of Black Providers is an Issue We Cannot Ignore
}

\author{
Emily Forrest Hutchens, MSPH
}

Keywords: collegiate-based emergency medical services; recruitment, retention, race | Corresponding Author and Author Affiliations: Listed at the end of this article.

\section{"Not everything that is faced can be changed. But nothing can be changed until it is faced." - James Baldwin}

$\mathrm{T}$ he modern model of Emergency Medical Services (EMS) in the United States was established over fifty years ago by a team of Black providers in an inner-city Pittsburgh neighborhood. ${ }^{1}$ Before the late 1960s, prehospital care was composed of little more than a transportation service in the backs of police cars and hearses, resulting in an epidemic of needless death en route to hospitals., ${ }^{2,3}$ In 1966, the National Academy of Sciences (NAS) brought attention to the problem in its white paper, Accidental Death and Disability: The Neglected Disease of Modern Society, which recommended that all communities implement EMS programs with standardized training and treatment protocols. ${ }^{4}$ However, Black Americans, who were already receiving disparate treatment in the medical field and beyond, recognized the need to build a system that could meaningfully serve their own community. ${ }^{1}$ Alongside White allies including Dr. Peter Safar, known as the "father of CPR," Freedom House Ambulance Service was established in 1967 with the dual purposes of answering the NAS call for emergency medical care in an organized system, while also addressing disparities in healthcare access and stable employment opportunities for Black citizens, who were barred from other types of skilled work. Freedom House demonstrated the feasibility of life-saving prehospital medical care that would be used to establish national standards for EMS training and education. ${ }^{1}$ Despite a record of lifesaving work, including being regularly called to medical emergencies in White communities, Freedom House's funding and EMS privileges in the city were transferred to a White EMS service in $1975 .^{1}$

Demographics of the modern EMS workforce reflect this shift, as data from the National Registry of Emergency Medical Technicians (NREMT) demonstrate that Black Americans only represent around 5\% of EMTs, with little change in the past decade. ${ }^{5,6}$ When the disquieting data on low EMS diversity first emerged from the NREMT in late $2019,{ }^{5}$ a conversation was sparked in the EMS community concerning race, asking whether a focus on diversity in the workforce would distract from a universal focus on providing the best care for all patients. While EMS research is a relatively young field that has rightfully focused on patient care, cuttingedge training, and even community paramedicine in the past few

Emily Forrest Hutchens, MSPH, is a Doctoral student in Health Behavior at the Gillings School of Global Public Health and an Emergency Medicine researcher with the School of Medicine at the University of North Carolina at Chapel Hill. years, research on the effects of low workforce diversity has yet to be meaningfully explored.

Research from a variety of clinical settings demonstrates that race can play a role in patient-provider communication, ${ }^{7,8}$ as well as provider decision-making, resulting in delayed or inappropriate treatment for minority patients. ${ }^{9,10,11}$ These disparities in communication and treatment spill over into patient outcomes, as demonstrated by studies such as one just last year showing that infant mortality for Black infants in the US is three times that of White infants, but that Black infants with Black doctors had significantly better outcomes. ${ }^{12}$ These studies arise from a variety of fields made up of providers who are committed to treating all patients alike, just like EMS providers. Despite this, research is continuously uncovering these underlying patterns of racial disparity.

Understanding that low provider diversity has the potential to impact our patients, the EMS research community must explore the "why" behind this phenomenon of low retention and recruitment of Black EMS providers. We can look again to other medical fields that have begun to explore the topic formally. The low rate of Black physicians has been attributed to the financial constraints and limited educational access to medical schools that disproportionately affect Black students. ${ }^{13,14}$ However, with a relatively accessible level of entry into EMS that allows high school students as young as sixteen to participate, as well as the lower cost and time commitment of EMS training courses relative to medical school, these explanations cannot be expanded far into EMS.

Studies that may be more applicable to EMS aim to describe the lived experiences of minority-race health professionals in the field. Research on minority stress theory demonstrates that minorityidentifying individuals who face prejudice or discrimination experience work-related stress at higher levels than their majority-identifying counterparts, even in already highly stressful situations. ${ }^{15}$ While all EMS professionals endure a role wrought with stressful and potentially traumatic situations, research among medical professionals has upheld this theory, demonstrating that Black physicians experience unique and outright racist interactions in their profession, leading to higher levels of stress. ${ }^{16,17}$

Only the experts in this lived experience can tell us whether this is happening in EMS - and they are. Black EMTs and Paramedics 
are documenting their lived experiences of racism in the field both formally and informally online. These providers describe patients refusing care and using racial slurs against them. ${ }^{18}$ Steven Nelson, EMS-I, earlier this year published his experiences as the only Black man in his Paramedic class and one of only a handful of Black providers in his EMS system, including hearing slurs used by both patients and colleagues. ${ }^{19}$

I had the opportunity to begin to explore the Black EMS provider experience as a formal research question in the summer of 2020, at the crossroads of the COVID-19 pandemic and national protests for racial justice, through a small and unfunded qualitative study. The project is limited in its scope and reach, and in the extent of my own analysis as someone who has not shared this experience but rather is viewing it as an outsider. Despite its limitations, preliminary results have demonstrated some of what we have seen in other medical professions: that Black EMS providers throughout the United States are facing racism in their role through interactions with others in the field. These interactions are coming from patients, strangers online, and even colleagues. This project can help us illuminate the experiences of Black providers in the arenas of EMS research and practice. What it cannot yet do is address the problem. Further research is critically and immediately needed to address not only the problem of low recruitment and retention of Black EMS providers, but also the highly stressful experiences these providers may face when they choose a career in EMS. The EMS research community has only taken the first step in describing this problem. It cannot be changed until it has been faced.

\section{References}

1. Edwards ML. Pittsburgh's Freedom House Ambulance Service: The origins of emergency medical services and the politics of race and health. J Hist Med Allied Sci. 2019;74(4):440-466. doi:10.1093/jhmas/jrz041

2. Shah MN. The formation of the emergency medical services system. Am J Public Health. 2006;96(3):414-423. doi:10.2105/AJPH.2004.048793

3. Caroline NL. Medical care in the streets. JAMA. 1977;237(1):43-46.

4. National Academy of Sciences (US) and National Research Council (US) Committee on Trauma; National Academy of Sciences (US) and National Research Council (US) Committee on Shock. Accidental Death and Disability: The Neglected Disease of Modern Society. Washington (DC): National Academies Press (US); 1966. doi:10.17226/9978

5. Crowe RP, Krebs W, Cash RE, Rivard MK, Lincoln EW, Panchal AR. Females and minority racial/ethnic groups remain underrepresented in emergency medical services: A ten-year assessment, 2008-2017. Prehosp Emerg Care. 2019;24(2):180-187. doi:10.1080/10903127.2019.1634167

6. Rivard MK, Cash RE, Mercer CB, Chrzan K, Panchal AR. Demography of the national emergency medical services WORKFORCE: A description of those providing patient care in the prehospital setting. Prehosp Emerg Care. 2020;25(2):213-220. https://doi.org/10.1080/10903127.2020.1737282

7. Shen MJ, Peterson EB, Costas-Muñiz R, Hernandez MH, Jewell ST, Matsoukas $\mathrm{K}$, Bylund CL. The effects of race and racial concordance on patient-physician communication: A systematic review of the literature. J Racial Ethn Health Disparities. 2018;5(1):117-140. doi:10.1007/s40615-017-0350-4

8. Schoenthaler A, Allegrante JP, Chaplin W, Ogedegbe G. The effect of patient- provider communication on medication adherence in hypertensive black patients: Does race concordance matter? Ann Behav Med. 2012;43(3):372382. doi:10.1007/s12160-011-9342-5

9. Morgan JR, Drainoni M, Christiansen C, Barlam TF. Patient-provider race and sex concordance: New insights into antibiotic prescribing for acute bronchitis. Journal of Health Disparities Research and Practice. 2017;10(4):6.

10. Hoffman KM, Trawalter S, Axt JR, Oliver MN. Racial bias in pain assessment and treatment recommendations, and false beliefs about biological differences between blacks and whites. Proc Natl Acad Sci U S A. 2016;113(16):42964301. doi:10.1073/pnas.1516047113

11. King WD, Wong MD, Shapiro MF, Landon BE, Cunningham WE. Does racial concordance between HIV-positive patients and their physicians affect the time to receipt of protease inhibitors? J Gen Intern Med. 2004;19(11):1146-53. doi: $10.1111 / j .1525-1497.2004 .30443 . x$

12. Greenwood BN, Hardeman RR, Huang L, Sojourner A. Physician-patient racial concordance and disparities in birthing mortality for newborns. Proc Natl Acad Sci U S A. 2020;117(35):21194-21200. doi: 10.1073/ pnas. 1913405117

13. Rao V, Flores G. Why aren't there more African-American physicians? A qualitative study and exploratory inquiry of African-American students' perspectives on careers in medicine. J Natl Med Assoc. 2007;99(9):986-93.

14. Roberts SE, Shea JA, Sellers M, Butler PD, Kelz RR. Pursing a career in academic surgery among African American medical students. Am J Surg. 2020;219(4):598-603. doi: 10.1016/j.amjsurg.2019.08.009

15. Meyer IH. Prejudice, social stress, and mental health in lesbian, gay, and bisexual populations: Conceptual issues and research evidence. Psychol Bull. 2003;129(5):674-697. doi: 10.1037/0033-2909.129.5.674

16. Beaumont CG. Exploring the experiences of racial identity and stereotype threat in African American male medical doctors. Seton Hall University Dissertations and Theses. https://scholarship.shu.edu/cgi/viewcontent. cgi article $=2848 \&$ context $=$ dissertations. Published 2012 .

17. Filut A, Alvarez M, Carnes M. Discrimination toward physicians of color: A systematic review. J Natl Med Assoc. 2020;112(2):117-140. doi: 10.1016/j. jnma.2020.02.008

18. Parker H. Black EMTs describe their experience working in the traditionally white field of emergency services. GoDanRiver.com. https://godanriver. $\mathrm{com} /$ news/local/black-emts-describe-their-experience-working-in-thetraditionally-white-field-of-emergency-services/article_3278fada-3c8a11e9-8365-2b71f698d96b.html. Published March 2, 2019.

19. Nelson S. My experience as a Black paramedic. Journal of Emergency Medical Services. https://www.jems.com/exclusives/my-experience-as-ablack-paramedic/. Published April 28, 2021.

Author Affiliations: From Gillings School of Global Public Health, School of Medicine, University of North Carolina at Chapel Hill - in Chapel Hill, NC (E.F.H).

Address for Correspondence: Emily Forrest Hutchens, MSPH | Email: ehutch@ med.unc.edu

Conflicts of Interest/Funding Sources: By the JCEMS Submission Declaration Form, all authors are required to disclose all potential conflicts of interest and funding sources. All authors declared that they have no conflicts of interest. All authors declared that they did not receive funding to conduct the research and/or writing associated with this work.

Authorship Criteria: By the JCEMS Submission Declaration Form, all authors are required to attest to meeting the four ICMJE.org authorship criteria: (1) Substantial contributions to the conception or design of the work; or the acquisition, analysis, 
or interpretation of data for the work; AND (2) Drafting the work or revising it critically for important intellectual content; AND (3) Final approval of the version to be published; AND (4) Agreement to be accountable for all aspects of the work in ensuring that questions related to the accuracy or integrity of any part of the work are appropriately investigated and resolved.

Submission History: Received December 30, 2020; accepted for publication July 27,2021

Published Online: August 10, 2021

Published in Print: August 10, 2021 (Volume 4: Issue 1)

Reviewer Information: In accordance with JCEMS editorial policy, Advice and Practice manuscripts are reviewed by the JCEMS Editorial Board and, as needed, independent reviewers. JCEMS thanks the Editorial Board members and independent reviewers who contributed to the review of this work.

Copyright: $\odot 2021$ Hutchens. This is an open access article distributed under the terms of the Creative Commons Attribution 4.0 International (CC BY 4.0) License, which permits unrestricted use, distribution, and reproduction in any medium, provided the original author and source are credited. The full license is available at: https://creativecommons.org/licenses/by/4.0/

Electronic Link: https://doi.org/10.30542/JCEMS.2021.04.01.01 


\title{
Lessons from Early Vaccination of Campus EMS Providers at the University of California, Davis
}

\author{
Lisa Mills, MD; Nathan Trauernicht, MPA, BS FPST, CFO, CEMSO, CTO, MIFireE; Nathaniel Hartinger
}

Keywords: collegiate-based emergency medical services; covid-19; vaccination | Corresponding Author and Author Affiliations: Listed at the end of this article.

$\mathrm{T}$ The University of California, Davis Fire Department's (UCDFD) experience obtaining the COVID-19 vaccine as a collegiate fire and emergency medical service (EMS) agency presented unique challenges. The objective of this piece is to highlight the barriers and solutions we faced during vaccine distribution. Key components of our successful vaccine program for EMS providers in an evolving pandemic environment included strategic planning of logistics supporting group appointments and protected time during shifts to attend vaccination appointments.

UCDFD provides emergency medical services, fire suppression, technical rescue, hazardous materials mitigation, and community risk reduction services for the collegiate campus and augments similar services in surrounding communities. The department is staffed by career firefighters, student firefighters, and student emergency medical technicians (EMTs). The university consists of a main academic campus, a medical campus, and satellite research facilities throughout California. The fire department is located on the academic campus. The medical campus is separated by 20 miles from the academic campus, a drive which ranges from 30 to 45 minutes, traffic dependent.

The medical campus obtained a supply of COVID-19 vaccines before the main campus, thus becoming the initial distribution site. Per the Centers for Disease Control and Prevention (CDC), as well as state and university vaccination plans, firefighters and EMTs are in the first priority group for COVID-19 vaccine access-classified as the phase $1 \mathrm{~A}$ vaccine group. Therefore, as university affiliates, providers in the UC Davis collegiate EMS agency were offered early access to COVID-19 vaccines available at the medical campus.

There were significant benefits to vaccination through the UC Davis Medical Center for our collegiate EMS agency. One was the early arrival of the vaccine. Distribution at the medical center began approximately one month before other EMS agencies in the area had access to the vaccine. Also, the medical center was able to support a 24-hours-a-day schedule, which enhanced flexibility and availability in scheduling. Another benefit was the pre-

Lisa Mills, MD is the Medical Director for the University of California - Davis Fire Department since 2018. Nathan Trauernicht, MPA, BS FPST, CFO, CEMSO, CTO, MIFireE, CA certified Fire Chief \#30 is the Fire Chief for University of California - Davis, providing overall leadership and direction to a department that serves a population of over 40,000. He has served the fire service since 1993. Nathaniel Hartinger is the Deputy Fire Chief for the University of California Davis Fire Department. He directs the Operations and Safety Division and has served the department since 1999. existing record-keeping capacity through occupational health for our employees. The pre-existing medical record system used by the university to manage employee health profiles precluded the need to newly account for employees, expediting the vaccination process. In addition, employees voiced satisfaction that their vaccination status automatically merged with their electronic health record.

We offered our EMTs and firefighters the option to obtain their vaccination during a shift, conferring additional benefits. First was limiting the impact on the employees' time off duty. Second was the ability to vaccinate as many employees as possible as soon as possible. In addition, there was consideration that peer support could enhance interest in the vaccine. If employees were asked to get their vaccine on their own time, this may have led to fewer members getting vaccinated.

There were several challenges with using the medical center for vaccination. When crew members got vaccinated during a shift, the one-hour round trip required taking an emergency response unit out of service. This was managed by taking one unit out of service and maintaining coverage with the other unit to keep the department in service. This process was coordinated by the county inter-agency automatic and mutual aid systems to ensure no lapse in coverage occurred.

An unforeseen impediment to this plan was that the medical campus vaccine scheduling system was conducted exclusively on an individual basis. This resulted in crew members on the same shift having appointments spread across more than an hour, causing unacceptably long lapses in service. Thanks to early collaboration with medical center clinic schedulers, crews were instead able to be accommodated as a group. The vaccine clinic was heavily staffed with limited appointments at this early phase in the process. Due to this, the staff was able to let all of the crew members into the vaccine clinic at the same time without undue burden on the clinic or shifting appointments.

Our approach to immunization for our collegiate EMS department was largely successful. Our first responders completed immunizations about one month ahead of other local fire and EMS providers and achieved a high rate of vaccination. We also had some employees change their decision to be in favor of vaccination when the crew was vaccinated as a group.

We have learned lessons that will enhance the success of collegiate 
EMS agencies during future mass, contemporaneous vaccination events. Group appointments should be readily accessible to minimize the time a crew is out of service. Protected time during a shift also enhances the accessibility of the vaccine. Crews attending appointments together led to employees getting vaccinated who otherwise may not have. In future efforts, we hope to create small mobile distribution units to further minimize time out of service while maintaining the advantages of providing group vaccination during work hours. Overall, our experience was that partnering with an academic medical center facilitated early vaccination.

Author Affiliations: From the University of California, Davis Fire Department - in Davis, CA (L.M., N.T., N.H.).

Address for Correspondence: Lisa Mills | Email: ldmills@ucdavis.edu

Conflicts of Interest/Funding Sources: By the JCEMS Submission Declaration Form, all authors are required to disclose all potential conflicts of interest and funding sources. All authors declared that they have no conflicts of interest. All authors declared that they did not receive funding to conduct the research and/or writing associated with this work.

Authorship Criteria: By the JCEMS Submission Declaration Form, all authors are required to attest to meeting the four ICMJE.org authorship criteria: (1) Substantial contributions to the conception or design of the work; or the acquisition, analysis, or interpretation of data for the work; AND (2) Drafting the work or revising it critically for important intellectual content; AND (3) Final approval of the version to be published; AND (4) Agreement to be accountable for all aspects of the work in ensuring that questions related to the accuracy or integrity of any part of the work are appropriately investigated and resolved.

Submission History: Received March 26, 2021; accepted for publication July 12, 2021.

Published Online: August 10, 2021

Published in Print: August 10, 2021 (Volume 4: Issue 1)

Reviewer Information: In accordance with JCEMS editorial policy, Advice and Practice manuscripts are reviewed by the JCEMS Editorial Board and, as needed, independent reviewers. JCEMS thanks the Editorial Board members and independent reviewers who contributed to the review of this work.

Copyright: () 2021 Mills, Trauernicht \& Hartinger. This is an open access article distributed under the terms of the Creative Commons Attribution 4.0 International (CC BY 4.0) License, which permits unrestricted use, distribution, and reproduction in any medium, provided the original author and source are credited. The full license is available at: https://creativecommons.org/licenses/ by $/ 4.0 /$

Electronic Link: https://doi.org/10.30542/JCEMS.2021.04.01.02 


\title{
Predicting Patient Volumes at Collegiate Football Games
}

\author{
Abagayle E. Renko, MD, NREMT-B; Joshua M. Knapp, MD; Susan J. Boehmer, MA; Joseph M. Kass; Dylan J. \\ Degol, MD; Jessica L. Mann, MD; Jeffrey S. Lubin, MD, MPH
}

\begin{abstract}
Background: Determining appropriate staffing and resources for mass gathering events (MGEs) such as college football games is challenging. Objective: We sought to create a model predictive of patient volumes at collegiate football games to help aid emergency medical services (EMS) in appropriate health care services planning. Methods: A retrospective review was conducted of patient EMS medical records from 99 Division I collegiate football games played across fourteen football seasons (2005-2018) at one outdoor stadium. A linear regression model with cross validation to the patient illness records was created, using the total number of patients as the outcome measure and variables that can be ascertained prior to game day as the predictors. Results: A formula was derived $(\mathrm{R} 2=0.70)$; predicted number of patients $=1.49+[5.91 \mathrm{x}$ parking lot hours $]+\left[1.12\right.$ x low temperature in $\left.{ }^{\circ} \mathrm{F}\right]+[-12.42$, if rain=yes $]+[18.34$, if snow $=$ yes $]+[-15.97$, if opposing team rank (OTR) is 11-25; -30.48 if OTR is $>25]+[-14.50$, if home team rank (HTR) is 11-25; -11.52 if HTR is $>25$ ]. Conclusion: Weather data, open parking lot hours prior to kickoff, and team rankings are important variables to consider when planning for necessary medical care at collegiate football games.
\end{abstract}

Keywords: mass gathering event, collegiate football, predicting patient volumes, patient presentation rate, transport to hospital ratio, emergency medical services

Corresponding Author and Author Affiliations: Listed at the end of this article.
$\mathrm{I}$ n 2019, collegiate football celebrated its 150 th anniversary. ${ }^{1}$ As the nation's second most popular sport, collegiate football drew nearly 50 million fans to games across all divisions and just under 34 million fans at Division I games alone during the 2018 season. ${ }^{1,2}$ As with any mass gathering event (MGE), along with the sport's popularity and consequently large attendance comes the expectation of patients requiring medical care as well as the potential for a mass casualty incident. Additionally, the majority of collegiate football stadiums are outdoor, thus subjecting their patrons to various weather elements and potentially affecting patient presentation rates (PPRs, or patients per 10,000 spectators) and transport to hospital ratios (TTHRs, or patients per 10,000 spectators transported from the event to the hospital via ambulance).

While the determination of appropriate staffing and resources necessary for any MGE is challenging, collegiate EMS agencies in

\footnotetext{
Abagayle 'Abby' Renko, BS, NREMT-B is a fourth year medical student at the Penn State College of Medicine in Hershey, PA and former Student Supervisor at the University Ambulance Service and for Beaver Stadium Emergency Medical Services (EMS) in University Park, PA. Joshua M. Knapp, MD completed his fellowship in EMS at Penn State Hershey Medical Center in Hershey, PA and is now an Emergency Medicine (EM) physician at Geisinger Holy Spirit Medical Center in Camp Hill, PA. Susan J. Boehmer, MA is a statistician for the Department of Public Health Sciences at the Penn State Hershey Medical Center in Hershey, PA. Joseph M. Kass is a graduate of Central Dauphin high school and an incoming freshman at The Pennsylvania State University with an interest in pursuing a career in EM. Dylan J. Degol, MD is a PGY-2 EM resident at Penn State Hershey Medical center. Jessica L. Mann, MD completed her fellowship in EMS and is now an EM physician at Penn State Hershey Medical Center in Hershey, PA. Jeffrey S. Lubin, MD, MPH, completed his EMS fellowship at the University of Pittsburgh Medical Center (UPMC) and is now the Vice Chair for Quality and Patient Safety and the Prehospital Division Chief at the Penn State Hershey Medical Center, Department of Emergency Medicine.
}

particular face unique challenges in attempting to plan adequate staffing for certain MGEs such as football games. Not only do collegiate EMS agencies tend to have higher staff turnover rates based on the natural time constraints immanent in hiring primarily college students, but both student organizers and medical providers at collegiate MGEs also tend to be relatively inexperienced in comparison to other prehospital providers. ${ }^{3}$ These characteristics further necessitate the need for an accessible model to predict patient volumes at collegiate football games so prehospital providers can prepare for appropriate event staffing and resource utilization.

Factors previously described in the literature known to affect patient volumes at MGEs, though not specific to collegiate football games, include weather, event type, event duration, event location (indoors or outdoors), time of day, day of week, patient age distribution, crowd mood and density, crowd intention, event attendance, and alcohol and drug use. ${ }^{4-8}$ Additionally, the crowds drawn to football games tend to require more medical attention than do less-animated spectators attending non-sporting events. ${ }^{9}$ Two studies have proposed models predictive of patient volumes at collegiate football games based on temperature alone, though none to our knowledge have attempted to perform a stepwise regression utilizing multiple variables, nor have any utilized only predictable factors easily accessible to event planners prior to the day of the event. ${ }^{10,11}$

This study aimed to create a model predictive of patient volumes at collegiate football games using only variables accessible to event planners prior to game day in an attempt to better explain variability of PPRs and TTHRs, improve overall resource utilization, and enhance staffing efficiency at MGEs. 


\section{Methods}

\section{Beaver Stadium EMS operations}

This study analyzed data from 'home' football games at Beaver Stadium located at Pennsylvania State University (Penn State) in University Park, PA. On football game days, all local 911 calls are re-directed to central dispatch in the stadium itself. The EMS dispatcher communicates with stadium EMS personnel after each 911 call and dispatches the appropriate basic life support (BLS), advanced life support (ALS), or BLS utility team based on predefined coverage areas. The stadium has one central First Aid station composed of a small waiting room and twelve individual patient 'rooms' which can accommodate up to eighteen patients on stretcher beds. This First Aid area serves as the base station for all football EMS operations and is typically staffed by at least one nurse and one physician. Any patients within the stadium who necessitate further assessment/care or require hospital transport are first transported from within the stadium to the First Aid station by one of approximately 17 BLS teams (number of teams may vary based on expected patient volumes) or five ALS teams. Additionally, one of the three agency ambulances is always kept in the stadium's South tunnel in the event a participating athlete suffers an injury requiring hospital transport. Each BLS team is equipped with a basic first aid kit and a Stryker stair chair, while ALS teams are each equipped with an oxygen tank, ambulatory monitor, and full transport stretcher. Any patients in the tailgate fields surrounding the stadium who require EMS attention either before or during the football game are typically assessed by one of five BLS utility teams, which are equipped with a basic first aid kit, Stryker stair chair, and patient stretcher. These patients are then transported by the utility team to the First Aid station for further care or for ambulance transport to the hospital.

On game days, the collegiate EMS agency staffs many BLS teams and some utility teams with both paid and volunteer crew members. Additionally, a significant portion of staff on these days (ALS teams, some BLS teams, some utility teams, and area supervisors) are paid staff members from other local EMS agencies. Medical students, resident physicians, and attending physicians from the Penn State Milton S. Hershey Medical Center in Hershey, PA also staff each game.

\section{Data collection}

Study data was collected for all 99 regular season 'home' football games played by the Penn State Division I collegiate football team at outdoor Beaver Stadium in University Park, PA between 2005 and 2018. The football seasons ran from late August to November of each year. Of note, alcohol is permitted in tailgate areas but prohibited within Beaver Stadium itself.

The patient data used for this study was collected by Beaver Stadium EMS staff through handwritten patient charts, then later de-identified and entered into a Microsoft Excel spreadsheet. All patients who sought medical attention, regardless of age or chief complaint, were included in the study.

Following patient data compilation, we retrospectively gathered weather data, team ranking data, and parking lot hours for each game, hypothesizing that these variables might play a role in patient volume prediction. Weather data, including daily high and low temperatures (in degrees Fahrenheit) and precipitation (rain or snow), were collected from the Penn State Department of Meteorology Joel N. Myers Weather Center website (http://www. meteo.psu.edu/ wjs1/wxstn/). Penn State and opposing team Associated Press Poll rankings, based on the week each game was played, were gathered from the Entertainment and Sports Programming Network's website (https://www.espn.com/) and confirmed using data from Sports-reference.com. Team rankings were further stratified into three groups: $1-10,10-25$, or $>25$; the $>25$ group included all teams that were unranked at the time of each game. Games in which Penn State played any team included in the Big Ten Conference were considered "in conference" games. Finally, the number of open parking lot/tailgate hours prior to kickoff was calculated based on game kickoff time. Per Penn State tailgate regulations, unless otherwise specified tailgate lots always open at 7:00am on days with a noon kickoff time and at 8:00am on days with all other kickoff times.

\section{Statistical analysis}

This study was approved by the Institutional Review Board at Pennsylvania State University's College of Medicine. Statistical analysis system (SAS) software (version 9.4) was utilized to fit a linear regression model with cross validation to the patient medical records using several variables: parking lot hours, daily high and low temperatures, precipitation, team rankings, and conference designation. A linear forward stepwise regression model was utilized with a selection removal and entry criteria of 0.15 and a five-fold cross-validation method, reviewing the predicted residual sum of squares at each step. Statistical significance was set at $\mathrm{p}<0.05$. Since we only had access to accurate attendance data for four of the 14 football seasons in our data set, we employed the total number of patients as our primary outcome measure rather than PPRs or TTHRs.

\section{Results}

Over a period of 14 football seasons, 99 games were played against opposing teams in Beaver Stadium. Of 5,384 total patients, 55\% were male and $45 \%$ were female. Patient ages ranged from less than one year to 92 years old, with a mean age of 35 years old. Most patients were seen within three hours after kickoff (62.4\%), though several were seen prior to kickoff (29.0\%) and few were seen after the game had ended (8.6\%). Alcohol intoxication was the most frequently documented chief complaint, followed by musculoskeletal injuries and head, eyes, ears, nose, and throat (HEENT) injuries (Supplementary Figure 1; Supplementary Table 1). The vast majority of patients (92\%) were spectators, and most were not Penn State students (65\%). Most patients were ambulatory upon arrival to the First Aid room (73\%), though 
Figure 1: Predictive model of patient volumes at Beaver Stadium, excluding three outlier games

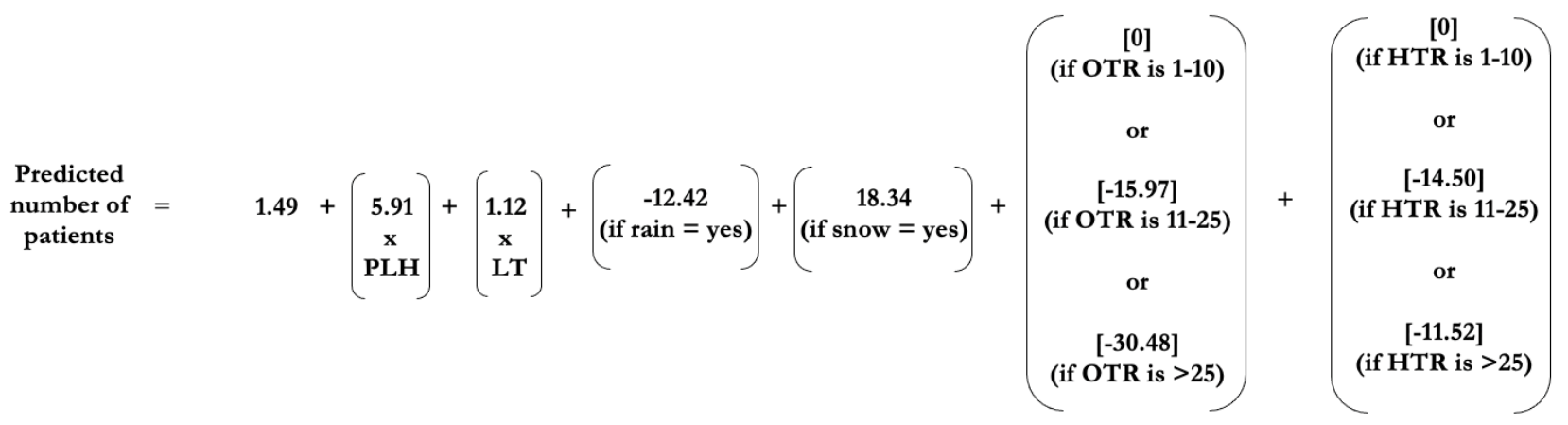

$* \mathrm{PLH}=$ parking lot hours; $\mathrm{LT}=$ low temperature; OTR $=$ opposing team rank; HTR $=$ home team rank

some arrived via ambulance stretcher (14\%) or wheelchair (13\%). Approximately one third of patients departed via ambulance (29\%), though most were ambulatory (59\%) and in minor condition (78\%) upon discharge. Only $21 \%$ and $1 \%$ of patients were discharged in moderate or severe conditions, respectively. Those that were ambulatory on discharge were given instructions to follow up with their primary care provider. Additionally, $3 \%$ were referred directly to the hospital but transported via private vehicle rather than by ambulance ('Hospital Referrals' column in Supplementary Table 2).

SAS initially determined that all variables except for conference designation were predictive of patient volumes in a linear forward stepwise regression model $\left(\mathrm{R}^{2}=0.64\right)$. The model's predicted patient volumes fell within 1 standard deviation $(\mathrm{SD})(\mathrm{SD}=17.9)$ of actual patient volumes $72 \%$ of the time (71 games), and within 2 standard deviations of actual patient volumes $97 \%$ of the time (96 games). Subsequent stepwise regression analysis was run following removal of three outliers, each deviating at least three standard deviations from the mean. In this new model (Figure 1) $\left(\mathrm{R}^{2}=\right.$ 0.70 ), opposing team rank, number of parking lot hours, and daily low temperature were the most highly significant predictors $(\mathrm{p}<$ $0.0001)$, followed by snow $(\mathrm{p}<0.01)$, Penn State rank $(\mathrm{p}<0.01)$, and rain $(\mathrm{p}<0.05)$. Refer to Figure 2 for a depiction comparing the actual patient volumes for each game to the volume predicted by our model and to Supplementary Figure 2 for a residual plot of predicted vs. actual patient count differences. The individual data for each game can be found in Supplementary Table 2 .

All individual variables considered in the development of this model were also examined separately as single predictors, and several linear trends were noted. Patient volumes and PPRs tended to increase along with rising temperatures (Figure 3; Figure 4$)\left(R^{2}\right.$ $=.37, p=0.0002$ ). Daily low temperature was more predictive of patient volumes in our model than daily high temperature. The mean number of patients at games with a low daily temperature below $30^{\circ} \mathrm{F}(\mathrm{n}=11)$ was $36($ median $=29)$ compared to a mean of 76 patients (median $=74$ ) on days with a daily low temperature

Figure 2: Comparison of predicted patient volumes to actual patient volumes at each Beaver Stadium football game from 2005 to 2018

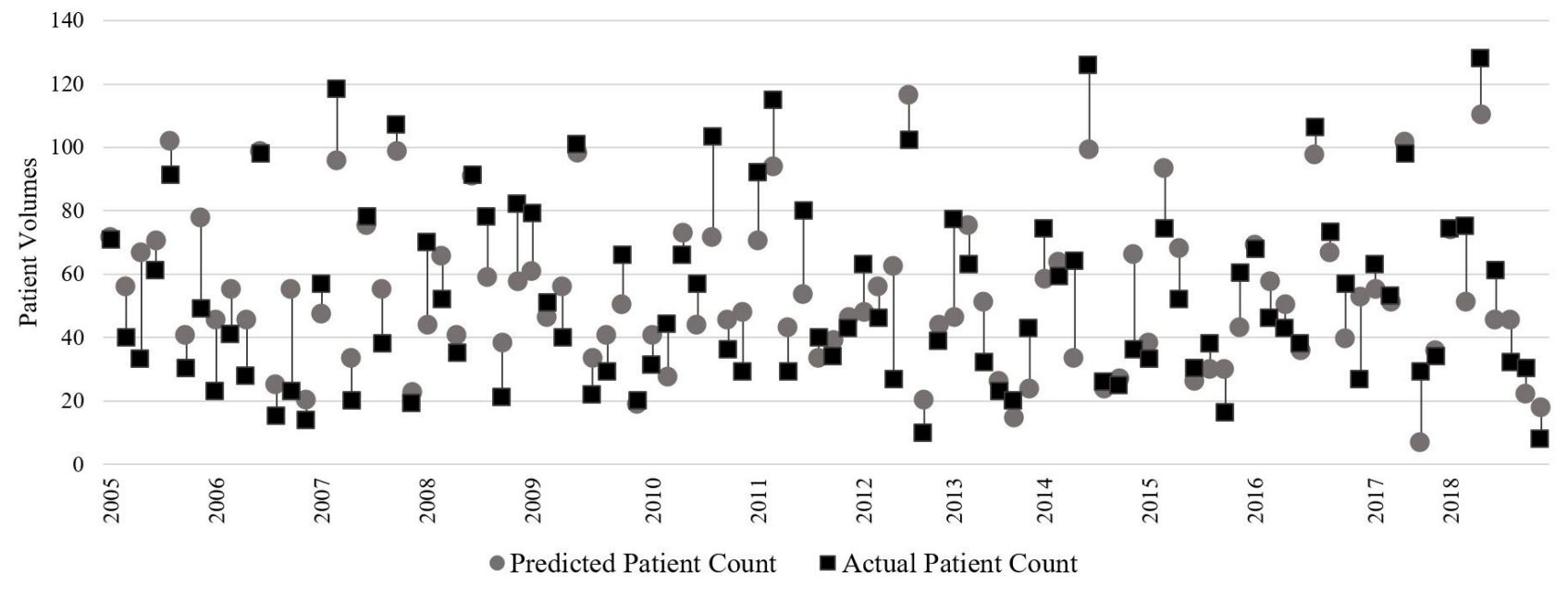


Figure 3: Relationship between patient volumes and daily low temperature, for all seasons (2005 to 2018)

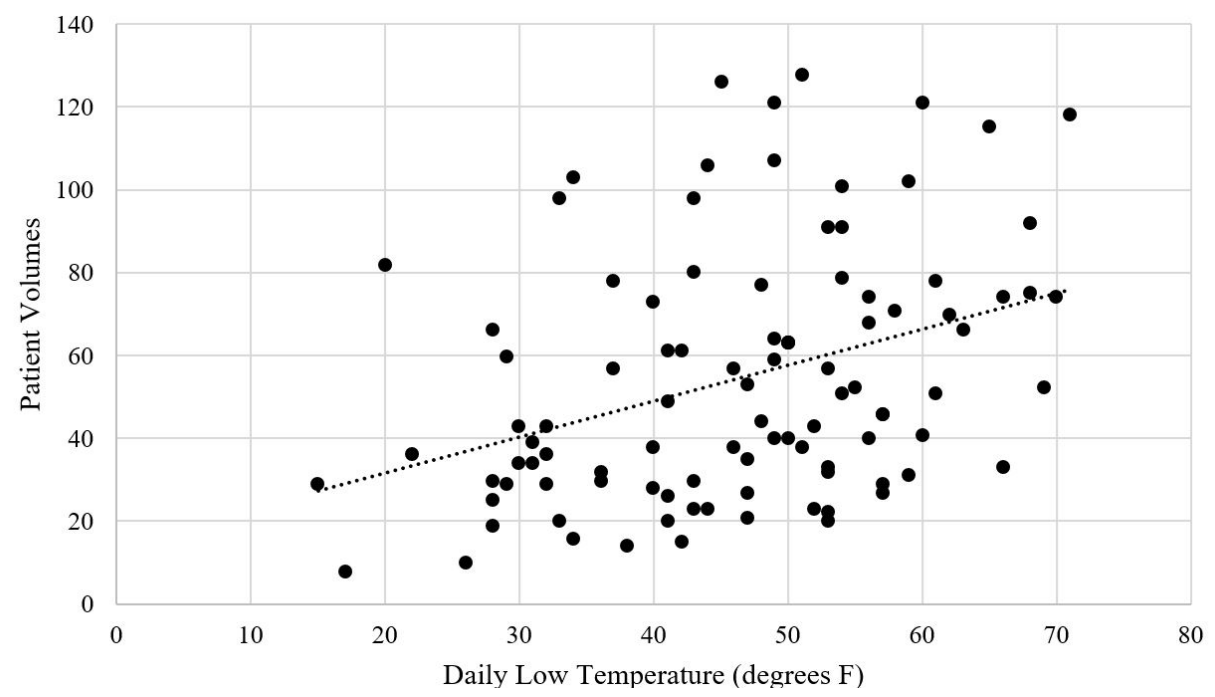

Figure 4: Relationship between patient presentation rates (PPRs) and daily low temperature, for seasons with attendance data (2015 to 2018)

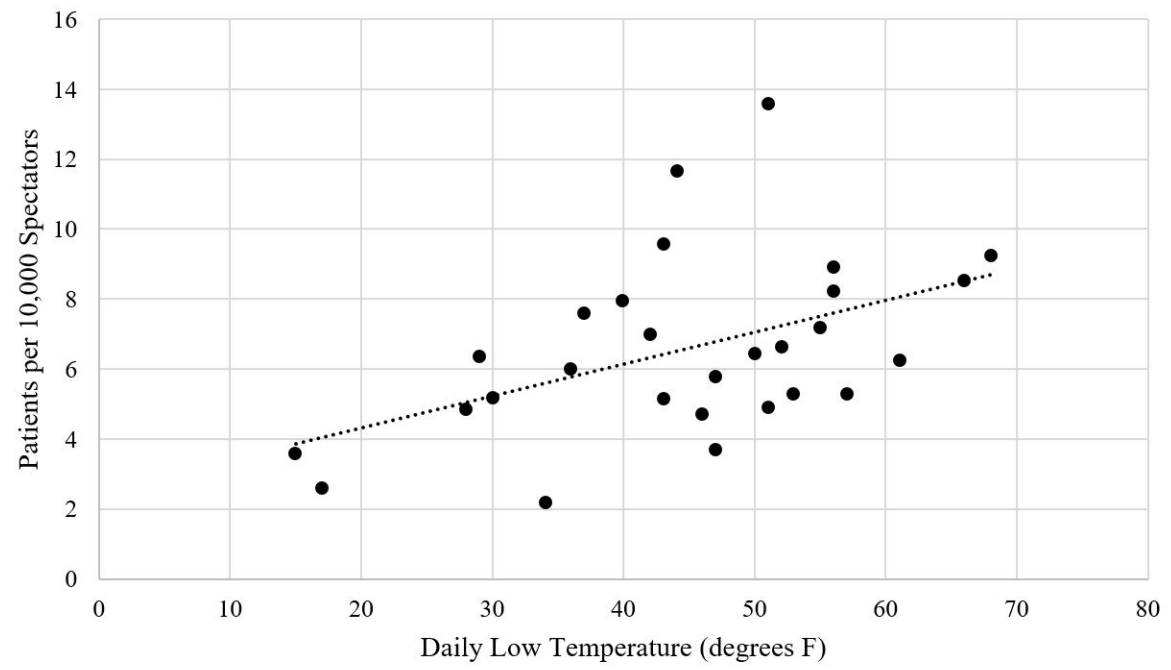

above $60^{\circ} \mathrm{F}(\mathrm{n}=12)(p=0.008)$. Games in which the opposing team's rank was 10 or lower were associated with the highest patient volumes; the mean number of patients for these games was 98 (median $=104)$ compared to means of 66 and 48 (medians $=61$, 41) for games played against opposing teams in the 10-25 and $>25$ (unranked) categories, respectively $(p<0.001)$. A similar yet not statistically significant association was noted between Penn State's team rank and patient volumes, increasing slightly with improved ranking $(p=0.23)$. Patient volumes were also positively associated with number of parking lot hours $(p<0.001)$. By contrast, patient volumes were inversely related to precipitation: games with rain averaged 50 patients (median $=39)(p=0.04)$ and games with snow averaged 43 patients (median $=35)(p=0.027)$, compared to 62 and 56 patients on average (medians $=62,52$ ) during games without any rain or snow, respectively. Conference was not found to have any association with patient volumes $(p=0.35)$. Of note, the variance inflation factors for all independent variables were very low, confirming that none were highly correlated with each other.

\section{Discussion}

A mass gathering event (MGE) is considered to be any event (planned or unplanned) where the attendance is sufficient to strain the planning and response resources of its host. The medical care provided to patients at these events including football games has been termed 'mass gathering medical care' (MGMC) by the National Association of EMS Physicians. ${ }^{10,12,13}$ Though few prior studies have attempted to erect a model predictive of patient volumes at collegiate football games specifically, several studies have attempted to build models predictive of patient volumes at various other types of MGEs such as other sporting events, music 
festivals, outdoor concerts, agricultural shows, and auto racing events.

The Zeitz method, based on one recurrent Australian agricultural event, suggests day of the week as a factor influencing patient volumes. ${ }^{5}$ The vast majority of collegiate football games, however, are played on the same day of the week, Saturday, with rare Friday evening games. The Arbon method, based on several Australian events in one calendar year, suggests crowd mobility, daily average humidity, presence of venue boundaries, whether the event involves sports, whether the event occurs during day or night, and whether the event is held indoors or outdoors as variables affecting patient volumes. ${ }^{6}$ Additionally, this model suggests that predicting patient load at MGEs is a nonlinear problem; for example, temperature seems positively correlated with patient volumes up to a certain point, above which patient volumes then decrease, presumably due to extra precautions taken by spectators in more extreme weather conditions. ${ }^{6}$ A later expansion of the Arbon method also incorporated attendance and patient age distribution as inputs in the model, though both must be estimated prior to game day as it is impossible to accurately ascertain them until after the event. ${ }^{5}$ Comparatively, the Hartman model does not utilize regression modeling but rather stratifies events into three different severity classes based on various event characteristics including heat index, presence of alcohol, crowd age, crowd attendance, and crowd intention. ${ }^{7}$

Despite these various attempts to predict PPRs and identify factors contributing to patient volumes, no widely accepted predictive model exists and thus most staffing and resource requirements at MGEs remain solely based on "local experience and anecdotal knowledge." ${ }^{14}$ While understaffing an event can increase risks to spectators by delaying their access to emergency care, consistently overstaffing events can become unsustainably expensive for institutions and their EMS agencies. ${ }^{3}$ Collegiate EMS agencies in particular face unique challenges in attempting to plan adequate staffing for certain MGEs such as football games. Many, if not most, event planners and organizers at collegiate EMS agencies are students. Therefore, by nature they are often less experienced in MGE planning than their counterparts at larger institutions. The high turnover rates and relative inexperience of student organizers and medical providers at collegiate MGEs necessitates a more accessible and accurate model to predict patient volumes and plan event staffing and resources. ${ }^{3}$ By examining data from several football seasons at a large collegiate stadium with a well-established EMS system, we were able to erect a model predictive of patient volumes which has the potential to help collegiate football event planners efficiently appropriate resources in advance of games.

Our original model underpredicted patient volume by more than 40 patients on two notable occasions: the Ohio University game in 2012 and the Michigan game in 2013. As these unique instances representing two of the three outliers across all our data coincided with major University-related events, patient volumes were likely influenced by social factors not taken into consideration by our model. The Ohio University game in 2012 was the first game played following the death of former longtime coach Joseph Paterno, with his successor Bill O'Brien serving as the new team coach. The 2013 Michigan game was a homecoming 'white out' game that Penn State won in four overtime periods despite its evening kickoff and subpar weather conditions. The third outlier was the Georgia State game in 2017, for which the model overpredicted by 38 points, likely due in part to a combination of Greek Life recruitment events, adverse weather conditions, and a string of several games in which Penn State had won by more than two touchdowns. For these reasons, we recommend taking into consideration major local, campus, and/or social factors that may influence attendance at any particular event. Initially erected to aid in the evaluation of factors contributing to injuries at one single event, Haddon's matrix may be useful in identifying social factors that contribute to event injuries as well as their interplay with other (individual, equipment, physical environment, and timing) event-related factors. ${ }^{15-17}$

Our analysis demonstrated that patient volumes tend to increase as temperature and parking lot hours increase, while volumes decrease with precipitation and opposing and 'home' team ranking numbers. Prior studies have shown an association between patient volumes and indicators of temperature and humidity such as heat index and dew point. ${ }^{18}$ While this data could be estimated prior to game day using predicted temperature and humidity, lack of access to historical humidity data prevented us from including these calculations in our model. Similarly, one published algorithm included expected attendance from ticket sales in its calculations of predicted patient volumes, and several other models incorporate some estimate of attendance. ${ }^{19}$ Despite our access to attendance rates for four football seasons, we excluded attendance as a factor in our model as it could not be accurately predicted prior to game day. For the seasons in which we had both expected attendance based on announced ticket sales and actual attendance data, we found dramatic discrepancies between the number of ticket sales and the actual game attendance (Supplementary Table 2). Forecasted weather data, as well as weekly team rankings and parking lot hours, are all consistent factors that any event planner should have access to at least one week prior to game day.

Several prior studies have demonstrated a positive relationship between temperature and patient volumes, both at collegiate football games and other MGEs. Kman et al. describe a nonlinear association between patient volumes and temperature at collegiate football games, observing a higher increase in expected number of patients for every 1 degree increase in temperature at higher temperatures. ${ }^{10}$ In a supplementary analysis, we found the validity of their model to significantly diminish below recorded temperatures of approximately $25^{\circ} \mathrm{F}$. For a hypothetical game with 100,000 spectators at $30^{\circ} \mathrm{F}$, their model predicts 79 patients. For the same number of hypothetical spectators at $20^{\circ} \mathrm{F}$ and $10^{\circ} \mathrm{F}$, however, it predicts 642 and 18,231 patients, respectively. This phenomenon might be explained by the exponential nature of their model and its utilization of temperatures recorded during each game's half time as its sole predictive variable; the half times during which a temperature 
was recorded all occurred between the hours of 12:40 and 20:40, and the lowest reported temperature for a game at either stadium in their data set was 38 degrees Fahrenheit. ${ }^{10}$ While our study found a positive relationship between temperature and patient volumes, it remains unclear why daily low temperature was more predictive of patient volumes in our model than daily high temperature. One could hypothesize this phenomenon may be partly due to the relation between the daily low temperature tending to occur around sunrise and the percent of games with noon kickoffs (42.4\%) where potential patients are participating in tailgate festivities earlier in the day.

In examining other weather data to include in our analysis, we originally combined both 'rain' and 'snow' into a general binary 'precipitation' variable. However, in separating that variable into 'rain' and 'snow' we discovered that our individual 'rain' variable was identical to our 'precipitation' variable because our data set did not include any games with snow but without rain. Therefore, we elected to include a 'snow' variable despite its lack of individual significance in an effort to improve generalizability across several EMS systems in different states with different baseline precipitations. Within our own data set, for example, we found that heat-related complaints were much more common in games without precipitation while hypothermia was more common in games with precipitation. Our hope is that inclusion of both 'rain' and 'snow' as separate variables, despite their synchronicity in our own data set, will allow our equation to more accurately predict patient volumes at both Northern programs with high annual snowfall and Southern programs with little to no snowfall.

Another variable difficult to quantify yet often integral in predicting patient volumes is the presence of alcohol at an event, as well as the interplay between alcohol availability and age distribution of the event's spectators. A well-established link exists between spectator age and alcohol in predicting patient presentations, with younger age demographics in environments that serve alcohol leading to an increased need for medical attention secondary to substancerelated medical complaints. ${ }^{20}$ However, one study found that the presence of alcohol at events was not significantly associated with PPRs. ${ }^{21}$ Though we could not control for alcohol consumption in our study, alcohol intoxication was by far the most common chief complaint of all patients in our data set. The mean age amongst those patients was 26 years old and the median was 21 years old, suggesting that half of patients treated for alcohol intoxication were under the legal drinking age, and most (75\%) of those intoxicated individuals under the legal drinking age were Penn State students. Future studies could explore how the permission of stadium alcohol sales affects those statistics and implications for the medical care needed at those events as a result.

Ultimately, the goal of erecting a model predictive of patient volumes is to create a tool useful to event planners for staffing and resource allocation prior to game day. Moving forward, event planners should consider not only the staffing levels appropriate based on the predicted number of patients, but also whether that staffing level remains adequate to prevent increased response times to patient incidents within and outside of the stadium itself. Additionally, the physical setups of collegiate football stadiums differ widely; though ours is arranged in a way that allows for easy access to and rapid transport of patients from any part of the stadium down to our First Aid station, not all stadiums have that luxury. For this reason, if choosing to decrease staffing levels based on a low predicted patient volume, organizations should also consider the need to adequately cover all sections of the stadium and maintain appropriate response times. We would also be interested to see how our transport to hospital ratios (TTHRs) per game (Supplementary Table 2) compare to those at similar Division I collegiate football stadiums without a First Aid station, as the original goal of implementing that treatment area at Beaver Stadium was to decrease TTHRs.

\section{Limitations}

Our predictive model is based on data from one collegiate football stadium and thus may be limited in predicting patient volumes at other Division I outdoor collegiate stadiums with different EMS infrastructures. Many variables could not be controlled for in this study, including number and age of spectators, environmental factors beyond temperature and precipitation, and consumption of alcohol. While alcohol has traditionally been prohibited from being served within Division I National Collegiate Athletic Association events, these restrictions on alcohol sales were eliminated in 2018. ${ }^{22}$ Though alcohol remains unavailable for purchase at Beaver Stadium during football games, our model may not be predictive of patient volumes at MGEs where alcohol is served throughout the game.

Additionally, our data contained a predictable association between low temperature and snow. This underlying relationship led to our model including snow as a positive term in the equation despite the inverse relationship between snow and patient volumes. Ultimately, we decided that the improved generalizability achieved via inclusion of the snow variable outweighed any effects secondary to the variable's inverse positivity.

Penn State also ranks amongst the highest collegiate football attendance in the country, behind only the University of Michigan; in 2018, home football games averaged an attendance of 105,485 per game. ${ }^{2}$ Comparatively, other Division I collegiate teams such as Rutgers University and Michigan State University averaged less than half of Penn State's attendance per home game between 20132017, at 45,891 and 34,266 respectively. ${ }^{23}$ Thus, our results may not generalize to all Division I collegiate football teams simply due to variation in game attendance and stadium capacity.

Additionally, though we did not retrospectively re-format our data to that of a minimum data set (MDS), we recognize the utility of using a MDS in future football seasons to collect patient and environmental data and standardize data collection across multiple MGEs. ${ }^{24,25}$ 


\section{Conclusion}

The prediction of patient volumes at collegiate football games, like other types of mass gathering events, is difficult and multifactorial. Our study suggests that examining forecasted weather data in conjunction with current team rankings may aid in this prediction. Though the use of retrospective data analysis and regression modeling lacks precision, it can help improve future patient volume prediction and aid in planning of appropriate health care services prior to collegiate football games.

\section{Acknowledgements}

We would like to thank James 'Dave' Jones (EMS Manager, Paramedic) and V. 'Josh' Fremberg (EMS Field Supervisor/ Instructor, Paramedic) of the Penn State University Ambulance Service (UAS) for their assistance in accessing and interpreting the data utilized for this project. We would also like to thank Jill Fremberg for her longtime efforts in patient EMS chart collection, organization, and consolidation on football game days; William 'Wes' Cartwright (Paramedic, former UAS EMS Supervisor) for his many years of service and significant contributions to the practice of collegiate event medicine; Tiffany Spiroff-Walstrom (UAS EMS Supervisor, Paramedic) for her continued service and contributions to the practice of collegiate event medicine; all past and current members of the Penn State University Ambulance Service and all other Beaver Stadium EMS staff members for their efforts in data collection and contributions to the practice of collegiate event medicine. Funding was not obtained for this research, nor do the authors have any conflicts of interest to disclose.

\section{References}

1. 2018-19 report: Amazing college football popularity highlighted by impressive ratings and attendance data (2019). National Football Foundation. https:// footballfoundation.org/news/2019/6/11/2018-19_Attendance_Release.aspx. Published June 11, 2019.

2. 2018 Football Attendance. NCAA. http://fs.ncaa.org/Docs/stats/football_ records/Attendance/2018.pdf. Published 2018.

3. Ordway EC, Sarna N, DeGeorge LM, Baird AM, Reid MJ, Nable JV. EMS resource utilization at college campus mass gathering events. J Coll Emerg Med Serv. 2018;1(2):24-30.

4. Milsten AM, Maguire BJ, Bissell RA, Seaman KG. Mass-gathering medical care: A review of the literature. Prehosp Disaster Med. 2002;17(3):151-62. doi: $10.1017 / \mathrm{s} 1049023 \times 00000388$

5. Zeitz KM, Zeitz CJ, Arbon P. Forecasting medical work at mass-gathering events: Predictive model versus retrospective review. Prehosp Disaster Med. 2005;20(3):164-168

6. Arbon P, Bridgewater F, Smith C. Mass gathering medicine: a predictive model for patient presentation and transport rates. Prehosp Disaster Med. 2001;16(3):150-158.

7. Arbon P, Bottema M, Zeitz K, Lund A, Turris S, Anikeeva O, Steenkamp M. Nonlinear modelling for predicting patient presentation rates for mass gatherings. Prehosp Disaster Med. 2018;33(4):362-367. doi:10.1017/ S1049023X18000493
8. Hartman N, Williamson A, Sojka B, Alibertis K, Sidebottom M, Berry T, Hamm J, O'Connor RE, Brady WJ. Predicting resource use at mass gatherings using a simplified stratification scoring model. Am J Emerg Med. 2009;27(3):337-43. doi: 10.1016/j.ajem.2008.03.042

9. Locoh-Donou S, Guofen Y, Welcher M, Berry T, O'Connor RE, Brady WJ. Mass-gathering medicine: a descriptive analysis of a range of massgathering event types. Am J Emerg Med. 2013;31(5):843-6. doi: 10.1016/j. ajem.2013.01.016

10. Kman NE, Russell GB, Bozeman WP, Ehrman K, Winslow J. Derivation of a formula to predict patient volume based on temperature at college football games. Prehosp Emerg Care. 2007;11(4):453-7. doi:10.1080/00207450701537043

11. Winslow JE. Retrospective review of relationship between spectator illness and temperature at division I football games. Ann Emerg Med. 2005;46(3):30.

12. Jaslow D, Yancy A, Milsten A. Mass gathering medical care: Position paper for National Association of EMS Physicians. Prehosp Emerg Care. 2015;4(4):359-60.

13. Emergency Preparedness Team. Public health for mass gatherings: key considerations. World Health Organization. https://www.who.int/ publications/i/item/public-health-for-mass-gatherings-key-considerations. Published January 1, 2015.

14. Zeitz KM, Schneider BN, Jarrett D. Mass gathering events: Retrospective analysis of patient presentations over seven years at an agricultural and horticultural show. Prehosp Disaster Med. 2001;585:1-14.

15. Haddon W. On the escape of tiger: An ecologic note. J Am Public Health Nations Health. 1970;60(12):2229-2234.

16. Arnold J. The London bombings and the Haddon matrix. Prehosp Disaster Med. 2005;20(5):278-281.

17. Hutton A, Savage C, Ranse J, Finnell D, Kub J. The use of Haddon's matrix to plan for injury and illness prevention at outdoor music festivals. Prehosp Disaster Med. 2015;30(2):175-183.

18. Perron AD, Brady WJ, Custalow CB, Johnson DM. Association of heat index and patient volume at a mass gathering event. Prehosp Emerg Care. 2005;9(1):49-52.

19. Nable JV, Margolis AM, Lawner BJ, Hirshon JM, Perricone AJ, Galvagno SM Lee D, Millin MG, Bissel RA, Alcorta RL. Comparison of prediction models for use of medical resources at urban auto-racing events. Prehosp Disaster Med. 2014;29(6):608-613

20. Bullock M, Ranse J, Hutton A. Impact of patients presenting with alcohol and/or drug intoxication on in-event health care services at mass-gathering events: An integrative literature review. Prehosp Disaster Med. 2018;33(5):539542.

21. Locoh-Donou S, Yan G, Berry T, O'Connor R, Sochor M, Charlton N, Brady W. Mass gathering medicine: Event factors predicting patient presentation rates. Intern Emerg Med. 2016;11:745-752.

22. Executive Regulations - Administration of NCAA Championships - Availability of Alcoholic Beverages, Division I Proposal 2017-122. NCAA Legislative Services Database. https://web3.ncaa.org/lsdbi/search/ proposalView?id=101871. Published April 25, 2018.

23. CollegeFootballNews.com. 2018 attendance rankings: Five-year average College Football News. https://collegefootballnews.com/2018/02/collegefootball-attendance-rankings-five-year-biggest-average. Published February $16,2018$.

24. Ranse J, Hutton A, Turris SA, Lund A. Enhancing the minimum data set for mass-gathering research and evaluation: An integrative literature review. Prehosp Disaster Med. 2014;29(3):280-289. 
25. Hutton A, Ranse J, Gray KL, Turris SA, Lund A, Munn MB. Environmental influences on patient presentations: Considerations for research and evaluation at mass-gathering events. Prehosp Disaster Med. 2019;34(5):552556.

\section{Supplementary Materials}

Supplemental Table 1: Chief Complaint Data from Penn State University Football Games Played at Beaver Stadium from 2005 to 2018 (available online)

Supplemental Table 2: Individual game data from Penn State University football games played at Beaver Stadium from 2005 to 2018 (available online)

Supplemental Figure 1: Patient chief complaints by organ system (available online)

Supplemental Figure 2: Residual plot of predicted vs. actual patient count differences at each Beaver Stadium football game from 2005 to 2018 (available online)

Author Affiliations: From Department of Emergency Medicine, Penn State Milton S. Hershey Medical Center - in Hershey, PA; Department of Emergency Medicine, Cooper University Hospital - in Camden, NJ (A.E.R.). From Department of Emergency Medicine, Penn State Milton S. Hershey Medical Center - in Hershey, PA; Geisinger Department of Emergency Medicine, Holy Spirit Medical Center in Camp Hill, PA (J.M.K.). From Department of Emergency Medicine, Penn State Milton S. Hershey Medical Center - in Hershey, PA (S.J.B., J.M.K., D.J.D., J.L.M., J.S.L.).

Address for Correspondence: Abagayle E. Renko, MD, NREMT-B | Email: renko-abagayle@cooperhealth.edu

Conflicts of Interest/Funding Sources: By the JCEMS Submission Declaration Form, all authors are required to disclose all potential conflicts of interest and funding sources. All authors declared that they have no conflicts of interest. All authors declared that they did not receive funding to conduct the research and/or writing associated with this work.

Authorship Criteria: By the JCEMS Submission Declaration Form, all authors are required to attest to meeting the four ICMJE.org authorship criteria: (1) Substantial contributions to the conception or design of the work; or the acquisition, analysis, or interpretation of data for the work; AND (2) Drafting the work or revising it critically for important intellectual content; AND (3) Final approval of the version to be published; AND (4) Agreement to be accountable for all aspects of the work in ensuring that questions related to the accuracy or integrity of any part of the work are appropriately investigated and resolved.

Submission History: Received September 12, 2019; accepted for publication June 21, 2021.

Published Online: August 10, 2021

Published in Print: August 10, 2021 (Volume 4: Issue 1)

Reviewer Information: In accordance with JCEMS editorial policy, Original Research manuscripts undergo double-blind peer-review by at least two independent reviewers. JCEMS thanks the anonymous reviewers who contributed to the review of this work.

Copyright: () 2021 Renko, Knapp, Boehmer, Kass, Degol, Mann \& Lubin. This is an open access article distributed under the terms of the Creative Commons Attribution 4.0 International (CC BY 4.0) License, which permits unrestricted use, distribution, and reproduction in any medium, provided the original author and source are credited. The full license is available at: https://creativecommons.org/ licenses/by/4.0/

Electronic Link: https://doi.org/10.30542/JCEMS.2021.04.01.03 


\title{
Assessment of Bystander Intervention on EMS Transport Decisions for Cases of Alcohol Intoxication at a Small Liberal Arts College
}

\author{
Bruno Di Nucci, BA, EMT-B; Adam Fallah, BA, EMT-B; Anamaria Alvarez, EMT-B; Parker Smith, EMT-B
}

\begin{abstract}
Background: Collegiate emergency medical technicians (EMTs) often encounter patients with uncomplicated alcohol intoxication who may refuse transport to an emergency department (ED), but research lacks on the influence of bystander intervention on an EMT's decision to let a patient refuse transport. Objective: We investigated how bystander intervention influences transport decisions in cases of alcohol intoxication at a small college in New York State. Methods: Data were collected from prehospital care reports (PCRs) archived by the college's emergency medical services between 2014 and 2018. Included data were collected on alcohol intoxication cases $(n=190)$ and categorized by transport decision, nature of bystander intervention, and patient's sex. Interactions between bystander intervention and transport decision were assessed by calculation of relative risks of ED transport and creation of a loglinear model. Results: Bystanders were present in a majority of cases, and a majority of bystanders offered to provide care following refusal of transport. Bystander presence was not associated with a significant difference in transport decision. However, when bystanders were present, offering care was associated with a $73 \%$ reduction in ED transport. Conclusions: Bystander care was found to be associated with a decreased relative risk of ED transport. However, documentation of bystander intervention in PCRs was often ambiguous. We highlight the need for better bystander intervention documentation in PCRs to improve research on this topic.
\end{abstract}

Keywords: alcohol, emergency department, bystander, intervention, documentation, collegiate-based emergency medical services

Corresponding Author and Author Affiliations: Listed at the end of this article.
$\mathrm{B}$ ystanders are often the primary actors in recognizing an emergency and activating emergency medical services (EMS). ${ }^{1-2}$ Their positive role has been extensively studied in cases of initiating cardiopulmonary resuscitation and intervening in potential sexual assault. ${ }^{1-3}$ Alcohol-related emergencies have the potential to benefit similarly from bystander intervention, as college students frequently seek help during alcohol emergencies. ${ }^{4}$ Meanwhile, underage binge drinking remains common among undergraduate college students. ${ }^{5-7}$ Because fear of legal or financial consequences may prevent students from seeking help, several college administrations have established amnesty policies for cases of alcohol emergencies, encouraging students to call for EMS.4, ${ }^{8-9}$ These amnesty policies have been associated with an increase in bystanders calling for emergency services during a crisis. ${ }^{8}$

Bruno Di Nucci, BA, EMT-B is a recent biology graduate of Bard College and a first-year osteopathic medical student at the University of New England. He is a former member of Bard Emergency Medical Services. Adam Fallah, BA, EMT-B is a recent chemistry graduate of Bard College, currently working for the Georgia Institute of Technology's COVID-19 research lab. He is a former member of Bard Emergency Medical Services. Anamaria Alvarez, EMT-B is a Senior psychology student at Bard College with a Concentration in Human Rights, and is a member of Bard Emergency Medical Services. Parker Smith, EMT-B is a Senior biology student at Bard College with an interest in public health and medicine, and is the Assistant Director of Bard Emergency Medical Services.
Additionally, research suggests that implementing educational programs to recognize the signs and symptoms of an emergency and perform basic safety measures tends to increase rates of bystander intervention across college campuses nationwide. . $^{3-12}$ However, the literature on the practical implications of bystander intervention still lacks research with regard to alcohol-related emergencies on college campuses.

EMS providers are often faced with the difficult decision of whether an intoxicated patient requires transport to an emergency department (ED), transport to a detoxification facility, or may be allowed to refuse further medical treatment and transport. These decisions have an important role in reducing the burden on EDs across the country, as inebriated patients incur $\$ 900$ million in hospital charges annually. ${ }^{13-14}$ In response to this issue, several communities have created detoxification facilities which provide limited medical care to non-critical patients. ${ }^{13-15}$ Finally, in many circumstances, patients have the ability to consent and express a desire to refuse further medical care and transport. In these cases, providers may play a notable role in discouraging this decision if they feel further care is warranted. Therefore, the outcome of an EMS interaction with an intoxicated patient is highly variable. While past reports have attempted to identify assessment 
criteria for triaging intoxicated patients by physical and mental presentation, past medical history, vital signs, and the provider's informed judgement, few reliable predictors of clinical outcomes have been identified. ${ }^{13-17}$

This study assessed the influence of bystander intervention on collegiate EMS transport decisions in alcohol intoxication cases. Considering that bystanders may be willing to take basic measures to ensure the safety of a patient, such as caring for them or providing them transport to further care facilities, ${ }^{4,-10}$ we hypothesized that final transport decisions may be related to either bystander presence at the scene or their willingness to provide care for patients refusing transport.

\section{Methods}

\section{Study design}

We performed a retrospective cohort study. Data were collected from handwritten paper prehospital care reports (PCRs) maintained by a collegiate EMS agency in New York State. ${ }^{18}$ PCRs were reviewed and considered for inclusion for every patient during the academic semesters from the fall of 2014 to the spring of 2018. The study was approved by the Bard College Institutional Review Board. Due to minimal risk posed to patients and the retrospective study design, it was determined that the study warranted a waiver of informed consent.

\section{PCR selection and interpretation}

Two inclusion criteria marked PCRs for selection: 1) alcohol use listed as a presenting problem, or 2) reference within the PCR narrative to the amount or type of alcohol ingested by the patient. PCRs that did not meet inclusion criteria were excluded from the study.

We defined any non-EMS person present at the scene and actively willing to contribute to the patient's care as a "bystander." While not necessary, bystanders were often people who already knew the patient prior to the incident, such as family, friends, roommates, and colleagues. Although there is no specific requirement in the standard PCR format to document bystander presence, EMS interactions with bystanders are typically included in the narrative portion of the PCR. Therefore, included PCRs were classified by whether or not bystander presence was documented. Among cases in which bystander presence was documented, PCRs were further classified by whether or not it was documented that bystanders were willing to care for the patient if they refused transport. This care may have included looking after the patient, sitting with the patient, providing private transport to further care, and/or offering to call for EMS again as needed.

Transport decisions were documented with a numerical disposition code at the bottom of the PCR, either 004 for ambulance transport to the ED or 005 for refusal of further medical care and transport. Outcome data was coded as either "Transport" or "No Transport."
In addition, patient sex was recorded as either "Male" or "Female." The general terms used to describe the data were chosen to deidentify the subjects as much as possible. For the same reason, we did not record data on other factors used to determine transport decision, such as presence of trauma or use of other drugs in addition to alcohol.

\section{Statistical analyses}

Relative risks (RRs) and 95\% confidence intervals (CIs) were determined for the associations between the three predictor variables (bystander presence, bystander care, and patient sex) and the outcome variable of transport decision.

Loglinear models using a Poisson distribution were employed to further analyze the interactions between categorical data variables. ${ }^{19-20}$ The best-fit loglinear model to account for the interactions between the variables was found using a likelihood ratio test to assess deviance from a saturated model that perfectly fit the data (significance value calculated on chi-squared distribution). ${ }^{19-20}$ The specific significant interactions between the modeled variables were determined through a three-way analysis of variance followed by a Tukey honest significant difference (HSD) post-hoc test. ${ }^{19-20}$

The calculations for RRs and CIs, loglinear models, statistical tests, and figures were done in RStudio (RStudio Team (2018). RStudio: Integrated Development for R. RStudio, Inc., Boston, MA, URL http://www.rstudio.com/, desktop version 1.2.1335), using the epiR package (version 1.0-4) for RRs and CIs and ggplot2 (version 3.2.1).

\section{Results}

During the academic years of 2014 through 2018, the collegiate EMS agency was dispatched to 190 cases of alcohol intoxication. These account for nearly one fifth (18\%) of the total calls responded to during that period. Among alcohol intoxication cases, $82 \%$ included bystander participation (Table 1). According to PCR narratives, $72 \%$ of bystanders offered to care for a patient following their refusal of transport (Table 1). In addition, 57\% of patients were female and $43 \%$ were male (Table 1).

As shown in Table 1, 32\% of alcohol intoxication patients were transported. Bystander presence vs. absence was not associated with a significant difference in risk of transport $(\mathrm{p}=0.92)$ (Figure 1). However, among cases with bystanders present, transport risk was significantly lower when bystanders offered care $(\mathrm{RR}=$ $0.27,95 \%$ CI $[0.17,0.43], \mathrm{p}<0.001$ ) (Figure 1 ). In the majority of cases involving bystanders that did not offer care, the patient was transported to the ED (Table 1). Risk of transport did not vary significantly by patient sex regardless of bystander status (Figure $1)$.

To further assess the interactions between bystander care and transport decision, we computed the frequencies of coincidences 
Table 1: Basic characteristics of all alcohol-involved cases at a New York collegiate EMS agency, 2014-18

\begin{tabular}{llcccc}
\hline & Total cases & $\begin{array}{l}\text { Proportion of } \\
\text { bystander cases } \\
(\mathbf{n = 1 5 5})\end{array}$ & $\begin{array}{l}\text { Proportion of total } \\
\text { cases (n= 190) }\end{array}$ & $\begin{array}{l}\text { Proportion } \\
\text { transported }\end{array}$ \\
\hline All patients & 190 & - & $100 \%$ & $32.1 \%$ \\
Bystander present & With care & 155 & $100 \%$ & $82 \%$ & $32.3 \%$ \\
& Without care & 112 & $72 \%$ & $59 \%$ & $15.2 \%$ \\
\hline No Bystander present & & 43 & $28 \%$ & $23 \%$ & $76.7 \%$ \\
Female patient & 35 & - & $18 \%$ & $31.4 \%$ \\
Male patient & 109 & $59 \%$ & $57 \%$ & $67.9 \%$ \\
\hline
\end{tabular}

between the variables and generated loglinear models of the data. ${ }^{19}$ We found that a homogenous association model, which accounted for all pairwise interactions between the variables and their frequencies, fit the data as well as a saturated model that accounted for all interactions between the variables to the frequencies (likelihood ratio test, Deviance $=0.096$, degrees of freedom $=2, \mathrm{p}=0.95)$. With the homogenous association model, we found a significant difference between the type of bystander intervention and the transport decision $(\mathrm{F}(2,2)=30.33, \mathrm{p}=0.03)$. Post hoc tests only showed statistically significant differences in three scenarios: not transported cases between bystander presence and bystander care $(\mathrm{p}=0.038)$, between transported cases without bystanders and not transported cases with bystander care ( $\mathrm{p}$ $=0.047$ ), and between not transported cases with and without bystander care $(p=0.045)$. Meanwhile, the effect of bystander intervention on transport decision did not differ much between sexes ( $\mathrm{p}>0.1$ for all pairwise interactions), suggesting little bias on transport decisions made toward either sex.

\section{Discussion}

Alcohol intoxication cases were a common occurrence for the collegiate EMS agency during the period of study. Bystanders participated in the majority of these cases, and a majority of bystanders offered to care for the patient. Approximately onethird of alcohol intoxication patients were transported.

Our data suggest that bystanders willing to provide care were influential in EMS decisions to let an alcohol intoxication patient refuse transport. Although the relative risk of ED transport for most predictor variables neared 1, the risk of ED transport was reduced by $73 \%$ when a bystander offering care was present at the scene. Post hoc analysis of our pairwise interaction model also found that transport decisions in cases with bystander care differed significantly from cases without bystander care. It is therefore likely that transport decisions made by the collegiate EMS agency were affected by the presence of a caring bystander. Of note, the

Figure 1: Bystander care lowers the relative risk of patient transport to the emergency department

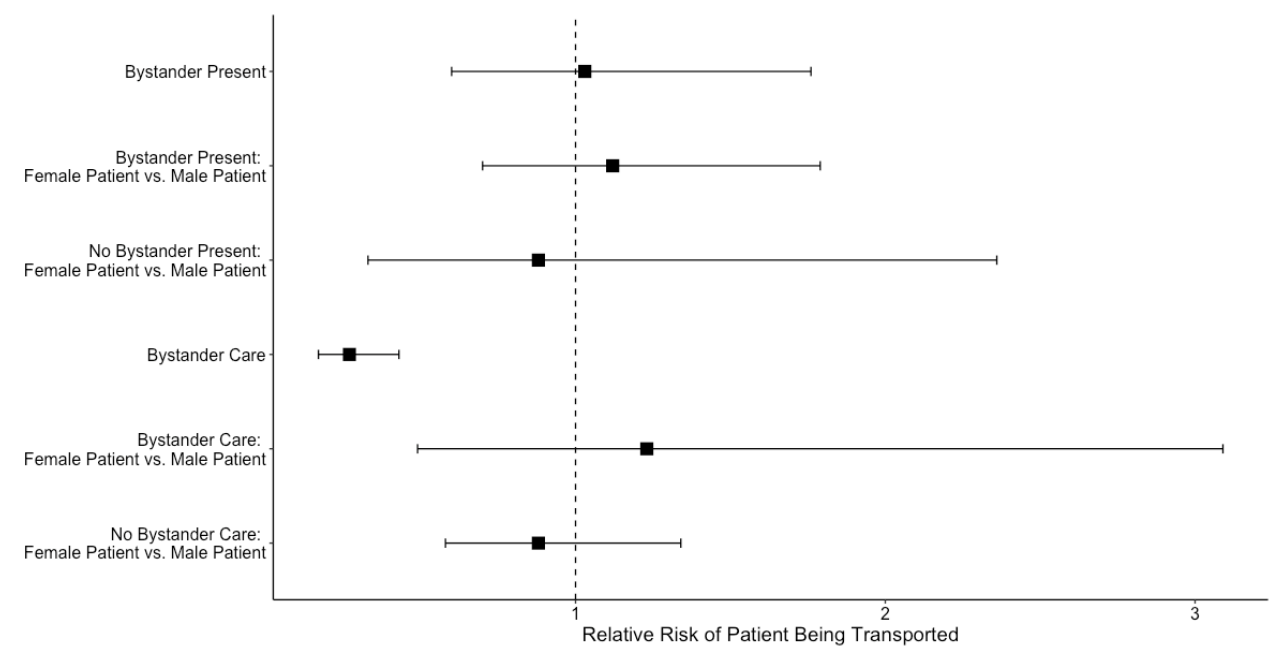

Black squares indicate the relative risk for each group comparison as noted on the vertical axis, with horizontal error bars indicating 95\% confidence intervals. No significant differences in risk of transport are noted by bystander presence or patient sex. When bystanders are present, risk of transport is significantly lower when bystanders offer care. 
presence of a bystander at the scene regardless of caring status was not found to reduce the risk of ED transport. However, because only three of all modeled pairwise associations between transport decision and bystander intervention were significantly different, it is hard to speculate the implications of the apparent reduction in ED transport related to bystander care in other scenarios.

In accordance with the previous literature, our data show that the effect of bystander intervention on transport decision did not differ by patient sex. ${ }^{8}$ This may be due in part to widespread bystander intervention education for students and campus medical amnesty policies. ${ }^{8}$

Our results suggest that a bystander's willingness to care for a patient can reduce the relative risk of transport to an ED. We speculate that this reduction might be related to the EMTs' and the patient's increased confidence that the patient will stay safe after EMS dismissal when a caring bystander is present.

\section{Limitations}

One challenge in conducting this study was that PCRs do not specifically require the documentation of bystander intervention. ${ }^{18}$ Therefore, it is probable that bystander presence or care was not documented in some cases, leading to a potential underestimation of the frequency of these events in our data. The inconsistency of bystander documentation also prevented a more detailed analysis. PCRs did not necessarily reveal the relationship of the bystander to the patient, so we could not assess differences in the influence of a family member, friend, roommate, or stranger on transport decisions. Also, while New York State protocols use the term "responsible adult" to describe someone who may care for a patient after refusal of EMS transport, ${ }^{17}$ there was not enough information in the PCRs to let us assess each bystander's level of "responsibility."

Our study did not consider several variables which may have informed interpretation of the results. These included several factors that may affect a transport decision following an alcohol intoxication call, such as the amount and type of alcohol consumed, signs of alcohol poisoning, the intake of illicit drugs, and presence of physical trauma. However, we judged that recording these factors would not be necessary as their incidence legally corresponds to a necessary transport to a hospital due to the established protocols in New York. ${ }^{17}$ Additionally, we could not assess patient outcomes following the final transport decision due to the prehospital nature of the archives.

Because we did not record patient names to comply with deidentification requirements, we were unable to determine if multiple PCRs referred to the same patient at the same event. For example, a patient may have initially been allowed to refuse further care and then required EMS intervention again due to worsening condition. Therefore, it is possible that our data contain instances of duplicated individuals.
Due to the textual nature of PCR narratives, interpretation of these narratives could potentially vary subjectively between observers. Consequently, our PCR interpretation process could have benefitted from an inter-rater reliability assessment.

Finally, this study was conducted in the specific environment of a small liberal arts college in New York State. Similar investigations in other collegiate and non-collegiate EMS settings are required to test the generalizability of the trends found.

\section{Conclusion}

Our data suggest that the presence of a caring bystander decreased the likelihood of transporting a patient with reported alcohol intoxication to an ED in a collegiate EMS setting. These decreases in likelihood were similar between male and female patients. Because of the trend shown in this retrospective study, it is important to raise awareness among collegiate EMS agencies about the potentially pivotal role that bystanders can play in a collegiate alcohol intoxication case. ${ }^{8-9}$ Bystanders may be a resource when transport is declined, but we recommend that EMTs keep protocols in mind and not bias their assessment of a patient solely due to the presence of a bystander at the scene. ${ }^{8,17}$ We propose that future understanding of patient outcomes after EMS dismissal-either to a hospital or to a bystander-and better documentation of bystander intervention in PCRs may improve how EMTs make decisions for the patient's best interest, ${ }^{8-9,17}$ as well as further research in this topic by other collegiate EMS agencies.

\section{Acknowledgements}

We would like to acknowledge the mentorship of Bard College faculty members Helen Epstein, $\mathrm{PhD}$, visiting professor of human rights and global public health, Arseny Khakhalin, $\mathrm{PhD}$, assistant professor of biology, as well as the mentorship of Dr. Angela Cavanna, DO, and thank all members of the Bard College EMS team. The authors did not receive any funding sources or grants to conduct this research. The authors declare no conflicts of interest.

\section{References}

1. Sayre MR, Berg RA, Cave DM, Page RL, Potts J, White RD; American Heart Association Emergency Cardiovascular Care Committee. Handsonly (compression-only) cardiopulmonary resuscitation: A call to action for bystander response to adults who experience out-of-hospital sudden cardiac arrest: A science advisory for the public from the American Heart Association Emergency Cardiovascular Care Committee. Circulation. 2008;117(16):2162-7. doi: 10.1161/CIRCULATIONAHA.107.189380

2. Iwami T, Kawamura T, Hiraide A, Berg RA, Hayashi Y, Nishiuchi T, Kajino K, Yonemoto N, Yukioka H, Sugimoto H, Kakuchi H, Sase K, Yokoyama H, Nonogi H. Effectiveness of bystander-initiated cardiac-only resuscitation for patients with out-of-hospital cardiac arrest. Circulation. 2007;116(25):29007. doi: 10.1161/CIRCULATIONAHA.107.723411

3. Katz J, Moore J. Bystander education training for campus sexual assault prevention: An initial meta-analysis. Violence Vict. 2013;28(6):1054-67. doi: 10.1891/0886-6708.vv-d-12-00113 
4. Oster-Aaland L, Lewis MA, Neighbors C, Vangsness J, Larimer ME. Alcohol poisoning among college students turning 21: Do they recognize the symptoms and how do they help? J Stud Alcohol Drugs Suppl. 2009;(16):12230. doi: $10.15288 /$ jsads.2009.s16.122

5. Krebs CP, Lindquist CH, Warner TD, Fisher BS, Martin SL. The Campus Sexual Assault (CSA) Study. Washington, DC: National Institute of Justice, U.S. Department of Justice; 2007.

6. Gidycz CA, Orchowski LM, Berkowitz AD. Preventing sexual aggression among college men: An evaluation of a social norms and bystander intervention program. Violence Against Women. 2011;17(6):720-42. doi: $10.1177 / 1077801211409727$

7. Ngo DA, Holstege C, Ding C, Miley L, Rege S. 173 validity of code-based recording of alcohol intoxication among college students presenting to a university hospital emergency department. Ann Emerg Med. 2017;70(4):S69-S70. doi:10.1016/j.annemergmed.2017.07.200

8. Lewis DK, Marchell TC. Safety first: A medical amnesty approach to alcohol poisoning at a U.S. university. Int J Drug Policy. 2006;17(4):329-338. doi:10.1016/j.drugpo.2006.02.007

9. Gondi S. Tackling Barriers to Seeking Emergency Care: The Campaign for a Medical Amnesty Policy at Washington University in St. Louis. J Coll Emerg Med Serv. 2018;1(1):19-24. doi:10.30542/JCEMS.2018.01.01.04

10. Megehee CM, Strick SK, Woodside AG. Overcoming bystander apathy and non-intervention in alcohol-poisoning emergency situations: Advancing field testing of training-for intervention theory via thought experiments. International Journal of Business and Economics. 2012;11(2):93-103.

11. Perez CE, Braslow A, Bock HC. National Standard Curriculum for Bystander Care. Washington, DC: U.S. Dept. of Transportation, National Highway Traffic Safety Administration; 1992.

12. O'Malley PM, Johnston LD. Epidemiology of alcohol and other drug use among American college students. J Stud Alcohol Suppl. 2002;(14):23-39. doi: $10.15288 /$ jsas.2002.s14.23

13. Ross DW, Schullek JR, Homan MB. EMS triage and transport of intoxicated individuals to a detoxification facility instead of an emergency department. AnnEmergMed.2013;61(2):175-84. doi: 10.1016/j.annemergmed.2012.09.004

14. Pletcher MJ, Maselli J, Gonzales R. Uncomplicated alcohol intoxication in the emergency department: an analysis of the National Hospital Ambulatory Medical Care Survey. Am J Med. 2004;117(11):863-7. doi: 10.1016/j. amjmed.2004.07.042

15. Leslom S, Patel S, Dezman ZDW. 64 component analysis of three screens for the out-of-hospital triage of patients with uncomplicated alcohol intoxication. Ann Emerg Med. 2017;70(4):S27-S28. doi:10.1016/j. annemergmed.2017.07.089

16. Marco CA, Brenner JM, Kraus CK, McGrath NA, Derse AR. Refusal of emergency medical treatment: case studies and ethical foundations. Ann Emerg Med. 2017;70(5):696-703. doi:10.1016/j.annemergmed.2017.04.015

17. New York State Bureau of Emergency Medical Services and Trauma Systems. Statewide Basic Life Support Adult And Pediatric Treatment Protocols. 2019 Version 1.0. New York State Department of Health. https://www.health. ny.gov/professionals/ems/docs/bls_protocols.pdf. Published April 12, 2019. Accessed November 30, 2019.

18. New York State Bureau of Emergency Medical Services and Trauma Systems. Prehospital care report (Version 5). https://www.health.ny.gov/professionals/ ems/pcr_5/index.htm. Published May 2013. Accessed December 2, 2019.

19. Ford C. An Introduction to Loglinear Models. University of Virginia Library Research Data Services + Sciences. https://data.library.virginia.edu/ an-introduction-to-loglinear-models/. Published July 12, 2016. Accessed December 10, 2019.

20. McKillup S. Statistics Explained: An Introductory Guide for Life Scientists. 2nd ed. Cambridge, MA: Cambridge University Press; 2011.

Author Affiliations: From Bard College; Bard College Emergency Medical Services - both in Annandale-on-Hudson, NY (B.D.N., A.F., A.A., P.S.).

Address for Correspondence: Bruno Di Nucci, BA, EMT-B | Email: bd1446@ bard.edu / bsouzadinucci@une.edu | Phone: (347) 346-2147

Conflicts of Interest/Funding Sources: By the JCEMS Submission Declaration Form, all authors are required to disclose all potential conflicts of interest and funding sources. All authors declared that they have no conflicts of interest. All authors declared that they did not receive funding to conduct the research and/or writing associated with this work.

Authorship Criteria: By the JCEMS Submission Declaration Form, all authors are required to attest to meeting the four ICMJE.org authorship criteria: (1) Substantial contributions to the conception or design of the work; or the acquisition, analysis, or interpretation of data for the work; AND (2) Drafting the work or revising it critically for important intellectual content; AND (3) Final approval of the version to be published; AND (4) Agreement to be accountable for all aspects of the work in ensuring that questions related to the accuracy or integrity of any part of the work are appropriately investigated and resolved.

Submission History: Received April 16, 2019; accepted for publication July 25, 2021.

Published Online: August 10, 2021

Published in Print: August 10, 2021 (Volume 4: Issue 1)

Reviewer Information: In accordance with JCEMS editorial policy, Original Research manuscripts undergo double-blind peer-review by at least two independent reviewers. JCEMS thanks the anonymous reviewers who contributed to the review of this work.

Copyright: () 2021 Di Nucci, Fallah, Alvarez \& Smith. This is an open access article distributed under the terms of the Creative Commons Attribution 4.0 International (CC BY 4.0) License, which permits unrestricted use, distribution, and reproduction in any medium, provided the original author and source are credited. The full license is available at: https://creativecommons.org/licenses/ by $/ 4.0 /$

Electronic Link: https://doi.org/10.30542/JCEMS.2021.04.01.04 


\section{The Journal of}

\section{COLLEGIATE EMERGENCY MEDICAL SERVICES}

The Official Journal of the National Collegiate Emergency Medical Services Foundation

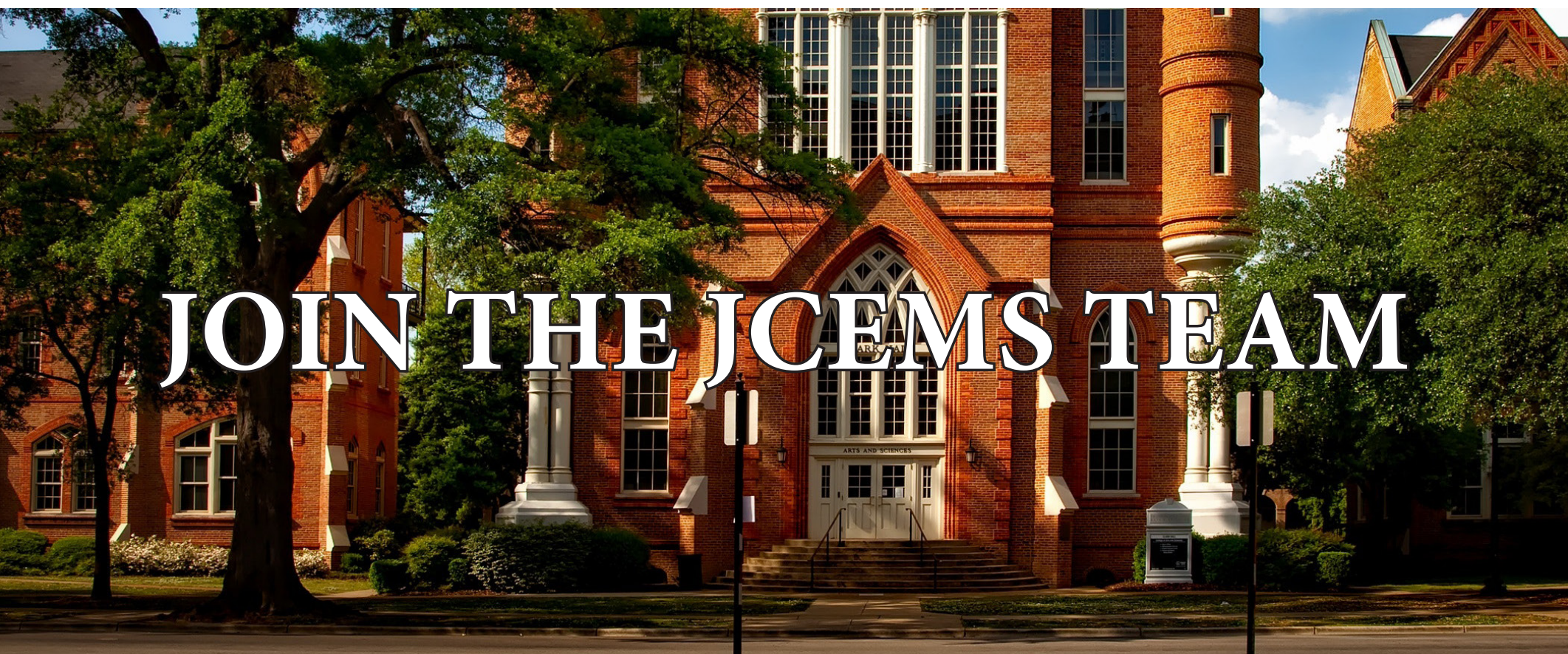

Now seeking motivated, passionate volunteers to join the JCEMS team. Available positions in the design, editing, and business management departments:

- Journalism \& Publishing

- Web Development \& Design

- $\quad$ Peer Review \& Copy-Editing

Excellent opportunity for current students and recent alumni to gain professional leadership experience in an innovative, scholarly publication.

For open positions, please email JCEMS@CollegeEMS. com or visit: www.collegeems.com/editorial-board

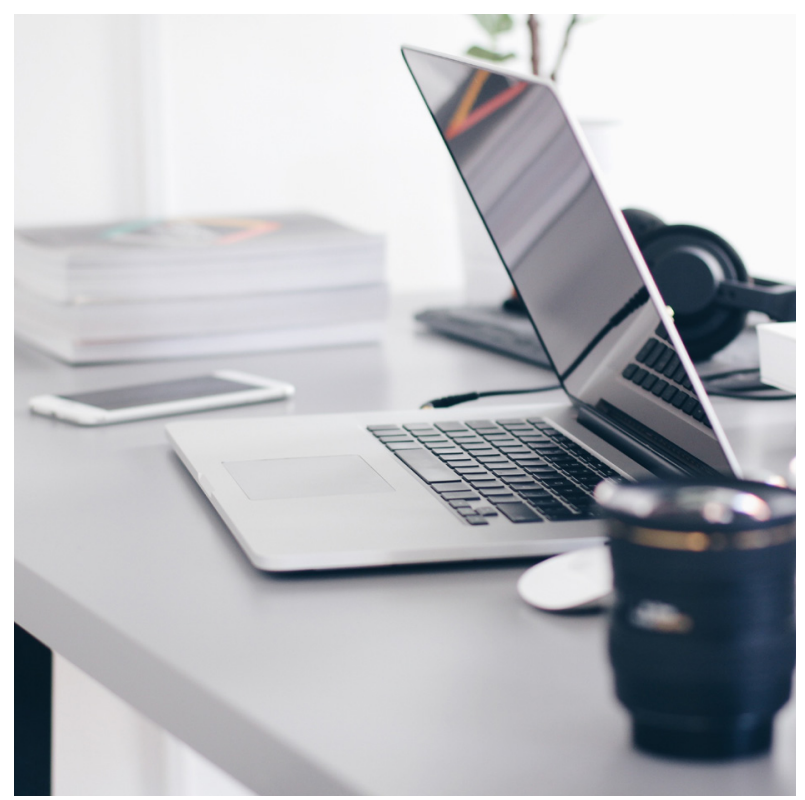


